VATT Working Papers 120

\title{
Open or Closed? How List Type Affects Electoral Performance, Candidate Selection, and Campaign Effort
}

Dominik Hangartner

Nelson A. Ruiz

Janne Tukiainen 


\title{
VATT WORKING PAPERS
}

\section{0 \\ Open or Closed? How List Type Affects Electoral Performance, Candidate Selection, and Campaign Effort}

\author{
Dominik Hangartner \\ Nelson A. Ruiz \\ Janne Tukiainen
}
Valtion taloudellinen tutkimuskeskus
VATT Institute for Economic Research Helsinki 2019


Corresponding author: Dominik Hangartner, Center for Comparative and International Studies, ETH Zurich, 8092 Zurich, Switzerland and Department of Government, London School of Economics and Political Science, Houghton Street, London WC2A 2AE, UK. Email: dominik.hangartner@gess.ethz.ch.

Nelson A. Ruiz, Department of Politics and International Relations, University of Oxford, Manor Road Building Manor Rd, Oxford OX1 3UQ, UK. Email: nelson.ruiz@politics.ox.ac.uk.

Janne Tukiainen, VATT Institute for Economic Research, Arkadiankatu 7, FI00101, Helsinki, Finland, and Department of Government, London School of Economics and Political Science, Houghton Street, London WC2A 2AE, UK. Email: janne.tukiainen@vatt.fi.

We thank Alexander Vega for his outstanding research assistance. We thank all the politicians who participated in our interviews. We are grateful to Allison Benson, Micael Castanheira, Torun Dewan, Jean-Paul Faguet, Salomo Hirvonen, Rafael Hortala-Vallve, Anthony McGann, Jim Robinson, Nicolas Sauger, Sandra Sequeira, Jim Snyder, Juuso Välimäki and Stephane Wolton, and seminar participants at APSA, EPSA, HECER, LSE-PSPE, Madrid, Paris and Zurich for helpful comments. The usual disclaimer applies.

ISBN 978-952-274-239-1 (PDF)

ISSN 1798-0291 (PDF)

Valtion taloudellinen tutkimuskeskus

VATT Institute for Economic Research

Arkadiankatu 7, 00100 Helsinki, Finland

Helsinki, July 2019 


\title{
Open or Closed? How List Type Affects Electoral Performance, Candidate Selection, and Campaign Effort
}

\author{
VATT Institute for Economic Research \\ VATT Working Papers 120/2019
}

Dominik Hangartner - Nelson A. Ruiz - Janne Tukiainen

\begin{abstract}
What effect does using open (as opposed to closed) lists in proportional representation elections have on party performance and the quality of candidate selection? We provide novel evidence by studying local elections in Colombia, where parties have discretion to field either open or closed lists. Using panel data covering the 1,100 Colombian municipalities for the 2003-2015 period, we leverage within-party, within-municipality, and over-time variation to identify the effect of ballot structure. We find that the adoption of open list dramatically increases parties' vote and seat shares. Semi-structured interviews with a representative sample of candidates reveal that parties that use closed list struggle to attract high-quality candidates and to incentivize them to campaign. Consistent with these mechanisms, our statistical analyses confirm that open-list candidates are more experienced, more engaged in their constituencies and campaigns, and less likely to have committed election fraud in the past.
\end{abstract}

Key words: Electoral Systems, Ballot Structure, Closed vs Open Party List, Political Selection

JEL classes: C23, D72 


\section{INTRODUCTION}

The design of electoral institutions has important consequences for the quality of democracy. Ever since John Stuart Mill's (1861) seminal works on democratic representation, scholars of

political science have explored the myriad ways electoral systems shape electoral competition (Duverger, 1954), incentives of parties and candidates to campaign (Iaryczower and Mattozzi, 2013), political selection (Carey and Shugart, 1995; Besley, 2005; Galasso and Nannicini, 2011; Meyersson, 2014), and electoral outcomes (Blais and Carty, 1990; Cox and Shugart, 1996; Cho, 2014; Herrera et al., 2014).

Electoral systems represent powerful instruments for institutional engineering (Norris, 2004), from major design features such as the form of representation (majoritarian or proportional) to seemingly small decisions, such as the structure of the ballot-which is the focus of this study. Proportional representation (PR) systems commonly use one of two ballot types: open or closed list. In open-list systems, voters select their preferred candidates from a party list, and the order in which candidates take seats is determined by the candidates' vote totals. By contrast, in closed-list systems voters cast their vote for a party, and the order in which candidates take seats is determined by their position on the party's list. The key difference between the two types of ballots is that open lists give voters not only influence over the number of seats each party wins, but also influence over which candidates from a given list win seats. This induces intraparty competition for votes (Blumenau et al., 2017; Braeuninger et al., 2019) while in closed-list systems, the party retains much higher levels of control.

The study of electoral systems has long been an important focus of political science (see, e.g., Grofman, 2008), yet scholars have only recently begun to explore the consequences of ballot structures used in PR systems. Some scholars argue that open lists create direct links between a candidate's performance and (re-)election, and thereby incentivizes good governance (Persson et al., 2003; Norris, 2004). Others argue that while intraparty competition induced by open lists rewards more experienced candidates (Shugart et al., 2005), it also incentivizes 
politicians to deliver particularistic services to their constituencies (Ames, 1995; Carey and Shugart, 1995; Crisp et al., 2004; Hallerberg and Marier, 2004; Ashworth and Bueno de Mesquita, 2006; Grimmer et al., 2012), and to engage in corruption (Chang, 2005; Chang and Golden, 2007). However, most of this research studies politicians' behavior solely under open lists or across countries, and therefore struggles to answer the central question that the theoretical arguments pose: how do the same voters, candidates, and parties behave under each system?

While political scientists increasingly exploit subnational variation to identify the effects of various dimensions of electoral systems - see, e.g., Fujiwara et al. (2011) on single- and dual ballot PR systems, Fowler (2013) and Bechtel, Hangartner, and Schmid (2016) on compulsory voting, Eggers (2015) on PR and plurality elections, and Fiva and Folke (2016) on seat allocation methods - we still lack empirical answers to some of the most basic questions about the consequence of ballot structure (Shugart, 2013), including: What are the effects of open and closed lists on electoral outcomes? How does ballot structure affect the quality of selected candidates? Can open lists - compared to closed lists - incentivize candidates to raise their campaign effort? This lack of evidence on the consequences of ballot structure is particularly problematic given that list $\mathrm{PR}$ is the most common election system in the world, with 70 of the 199 countries considered by Reynolds, Reilly, and Ellis (2008) using some variant of it.

We make considerable progress on answering these questions by studying the unique PR system of Colombia, where local parties can use open or closed lists in municipal elections. Since the electoral reform of 2003, local parties can decide to use open or closed lists in each election cycle, and also change ballot structure across elections. This complete discretion over list type leads to within-party, within-municipality, and over-time variation in the adoption of open or closed lists. To leverage this variation, we collect party- and candidate-level panel data for the 1,100 Colombian municipalities over four elections between 2003 and 2015. In a first step, we employ panel data models to estimate the effect of list type on vote shares by 
comparing the same party in the same municipality in consecutive elections, once under closed and once under open list. We find that parties enjoy a $64 \%$ higher vote share and a $75 \%$ higher seat share when using an open ballot structure.

By drawing on insights from semi-structured interviews with a representative sample of candidates, we explore potential explanations for these large effects. We uncover evidence for three main mechanisms. First, we find that open lists induce all candidates, independent of their initial ranking, to campaign. This is not the case under closed lists, since lower-ranked candidates with little chance of winning a seat have few incentives to campaign. Second, the interviewees suggest that open lists better attract high-quality candidates than closed lists. Analyzing a broad set of pre-election quality indicators - covering candidates' experience, constituency engagement, and fraudulent voting behavior - confirms this suggestion: Average candidate quality is significantly higher on open lists. These quality differences are particularly pronounced among lower-ranked candidates. Third, we find that open lists persuade more candidates to run for office and expand the party's total campaign effort. In sum, we find that by adopting open lists, parties can increase their vote share, incentivize all candidates to campaign, and attract more - and more experienced and higher-quality - candidates.

The dramatic increases in vote and seat shares that we document for open list constitutes some of the first credible empirical evidence of the effect of list type on electoral outcomes in a real-world setting. In contrast, most prior studies (e.g., Bergman et al., 2013; Nemoto and Shugart, 2013) of list effects are limited by a lack of within-country and over-time variation in ballot structure, thereby raising the concern that unaccounted-for heterogeneity between countries, rather than list type, may be driving the results. ${ }^{1}$ Since our research design leverages subnational, within-party and over-time variation, we believe our estimates approach to

\footnotetext{
${ }^{1}$ To our knowledge, there are three exceptions: (Sanz, 2015) investigates the impact of closed list PR versus open list plurality-at-large system (not PR) on turnout by exploiting population thresholds that determine the list type in Spanish local elections. Blumenau et al. (2017) rely on a survey experiment to study the effect of open- versus closed-list PR on vote choice in the UK, and Braeuninger et al. (2019) use a similar survey experiment to study vote choice in Germany.
} 
the causal effects of open and closed lists. This interpretation is supported by a variety of robustness tests and supplementary analyses that hold candidate quality constant and suggest that our results are unlikely to be driven by confounders or reverse causality.

Our empirical evidence on the causal mechanisms through which electoral institutions affect incentives and behavior of parties, candidates and voters contribute to the study of political selection. Recently, there has been renewed interest in political selection (see, e.g. Dal Bó et al., 2017; Dal Bó and Finan, 2018) and democracy's ability to attract competent politicians. We document how ballot structure in PR systems has important consequences for the quality of candidate selection, and thereby contribute to filling a void identified in the American Political Science Associations' Task Force Report on Electoral Rules and Democratic Governance (Shugart, 2013).

Given their detrimental impact, we explore why any party would choose closed list. Several candidates we interviewed asserted that closed lists increase party cohesion and send voters an important signal about party cohesion. We find that mostly new parties adopt closed lists, and that they tend to switch to open lists for subsequent elections. This suggests that parties learn of the detrimental impact of closed lists on electoral performance through experience. This resonates with existing work on how the incentives that politicians face influence the (endogenous) formation of political institutions (Aghion et al., 2004, 2007; Leemann and Mares, 2014). ${ }^{2}$ Simultaneously, our results also contribute to the recent theoretical and empirical literature on how electoral institutions shape the incentives of candidates and intra-party politics (Buisseret and Prato, 2018).

A related literature explores the consequences of primaries. Parties' decision to adopt primaries is structurally similar to the choice between open and closed lists, as primaries also involve a trade-off between maintaining party control and ensuring popularity among voters (e.g Snyder and Ting, 2011; Serra, 2011, 2013; Hortala-Vallve and Mueller, 2015). Our

\footnotetext{
${ }^{2}$ In related work and leveraging Colombian parliamentary elections, Achury et al. (2017) study the determinants of why parties choose open or closed lists.
} 
findings corroborate these studies by showing that open lists - which like primaries are an "open" procedure - increase vote shares and candidate quality.

One might wonder what, if anything, we can learn from studying Colombia's very particular mixed-ballot system for our general understanding of ballot structures. While rare, the mixedballot system of Colombia is not unique. For example, the Danish election law also grants parties a choice between open and semi-open list, and we would expect that the sign of the relationships that we document here would be the same for this case. A broader question concerns the inferences we can draw from Colombia's mixed-ballot system to a polity with a pure open- or closed-list system. As we discuss in more detail in the conclusion, we believe that the main mechanisms connecting closed lists to candidate selection and behavior would also hold outside of the Colombian context, and that even in a pure closed-list system, parties will face similar difficulties in attracting high-quality candidates and in incentivizing them to campaign.

The rest of the paper proceeds as follows. In the next section, we describe the institutional context and the Colombian election law that grants parties discretion over the list type. In Section III, we describe our novel dataset covering all municipal elections for the 2003-2015 period and discuss the descriptive statistics. Section IV details the empirical strategy. Section $\mathrm{V}$ presents the main results on the effect of list type on electoral success. Section VI combines insights from qualitative interviews and quantitative analyses to shed light on the mechanisms driving our main result. These sections also provide extensive robustness checks and additional analyses to address concerns about reverse causality. Section VII examines why any party would choose closed lists given their detrimental impact. Section VIII concludes by discussing the generalizablity of our findings and avenues for further research. 


\section{Election LaW Reform in Colombia}

Colombia has the third-largest population and the fourth-largest economy in Latin America. While endowed by rich natural resources, the country is characterized by large economic and social heterogeneity across regions, and high levels of inequality (Bushnell, 1993). For most of the 20th century, Colombia had a strong central government and a bipartisan system in which either the Conservative or Liberal Party held the presidency. In the last decades of the 20th century, several reforms were enacted to counterbalance the strong bipartisanship and to decentralize the political structure. Inter alia, these reforms introduced elections for local mayors and devolved financial authority to the regions. In the 1990s, third parties began to play a stronger role and increase their presence at the local level (Hoyos, 2005), and the political landscape began to resemble the typical multiparty setting often observed in PR systems.

Colombia consists of about 1,100 municipalities ${ }^{3}$ located within 32 departments. At the local level, politicians are selected for local administrative juntas (in only a handful of municipalities), municipality councils, municipality mayors, department assemblies, and governors for each department. The main role of the local councils, which are the focus of this study, is to approve the annual budget and projects proposed by the municipal mayor. The council size is a function of population registered in the municipality.

Before the 2003 election law reform, parties presented multiple candidate lists for each district (Shugart et al., 2005). Instead of running on a common party list, most candidates would run on their own list to take advantage of the PR formula, which benefited small lists. By 2002 nearly all lists consisted of a single candidate, which led to a high degree of fractionalization and made local politics highly personalistic (Shugart et al., 2005; Pachón and Shugart, 2010).

To address these issues, the 2003 reform limited each party to a single list in municipal and national elections. Proponents of open- and closed-list systems were not able to agree on

\footnotetext{
${ }^{3}$ The exact number varies during our period of analysis, since a few new municipalities were created between 2003 and 2015.
} 
a single list type, so they decided to let parties choose the list type for each district they ran in (Shugart et al., 2005). While the party ranks the candidates under closed list, under open list voters can choose to vote for the party as a whole ${ }^{4}$ or for any person on the list. Figure 1 presents an example of a mixed ballot, consisting of both open and closed lists, for a local election in the municipality of Abejorral; the upper-right most party (MOIR) is the only one that fielded a closed list.

Figure 1: Example of a mixed ballot in Colombia, 2003

CONCEJO DE ABEJORRAL(ANTIOQUIA) -01004CO-

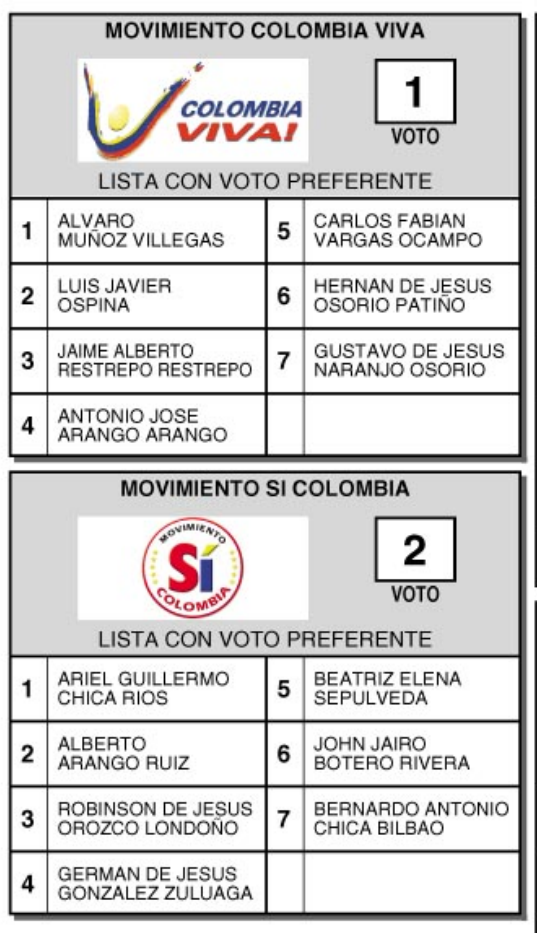
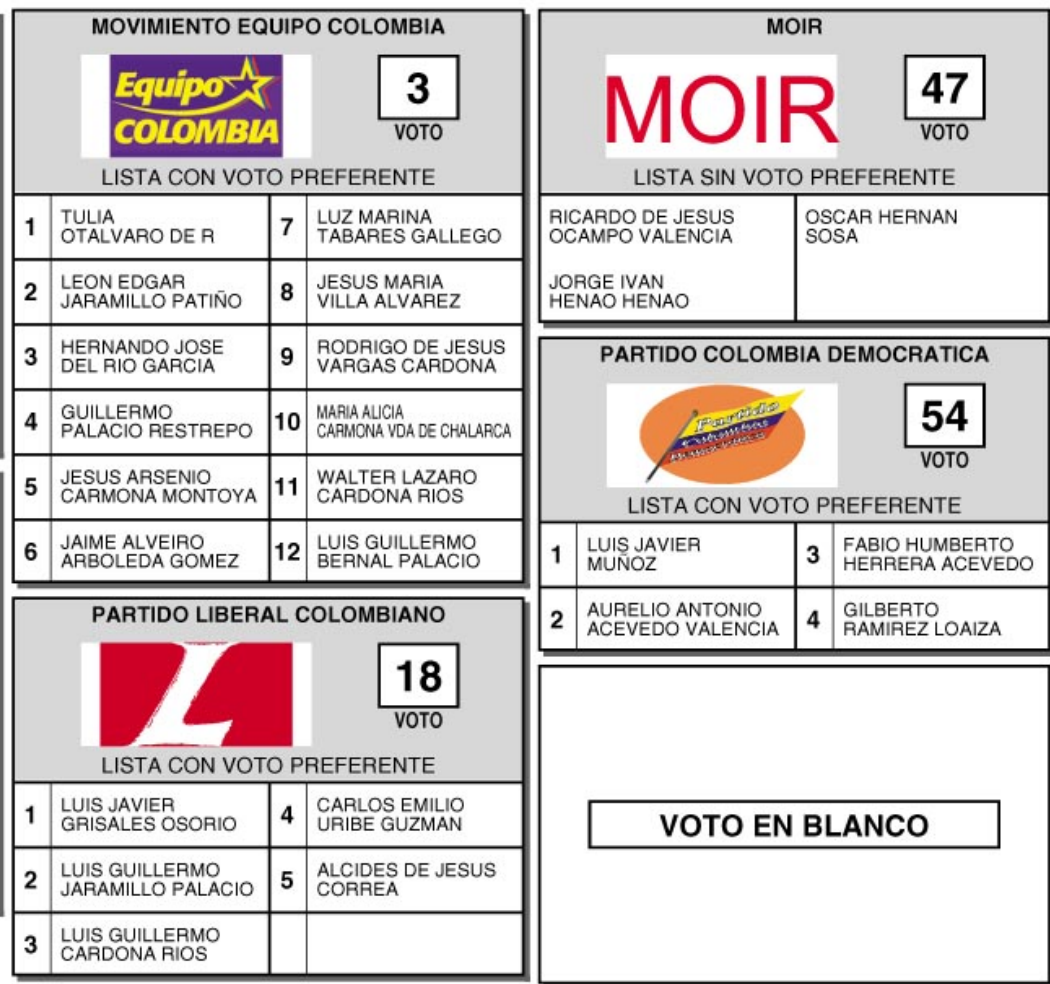

HENAO HENAO

PARTIDO COLOMBIA DEMOCRATICA
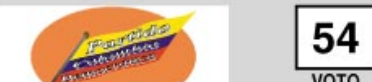

LISTA CON VOTO PREFERENTE

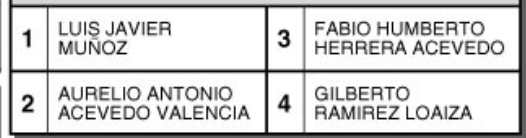

Source: National Registry Office.

VOTO EN BLANCO

Parties must decide on a list type three months before an election, a few days before the official start date of the campaign. The list type and the candidates running are announced

\footnotetext{
${ }^{4}$ These votes increase the party total but do not alter the ranking of candidates. Of all open lists cast for local council elections between 2003 and 2015, on average only $9 \%$ of the votes were cast for parties rather than specific candidates.
} 
simultaneously. Appendix Table A1 details this timeline for the 2015 election cycle. Our qualitative interviews with local politicians revealed that decisions about list type are typically made by local party leaders: either a core group of local candidates or a single party leader. This power of local candidates is likely a consequence of the general weakness of national parties in Colombia (Shugart et al., 2005).

\section{Data And MeAsures}

Our analysis focuses on local elections for municipal councils, which provide sufficient variation in ballot structure and a sizeable sample. We employ the electoral data compiled by Pachón and Sánchez (2014), which is based on records collected by the Colombian national electoral authority (Registraduría Nacional del Estado Civil). We updated these data with the 2015 election results provided by the Registraduría such that resulting database covers the 20032015 local elections in all municipalities. ${ }^{5}$ This database contains information on the parties participating in local council elections, the candidates, and the votes for each candidate or list.

In order to unterstand the effect of ballot structures on candidate selection and behavior, we construct a novel dataset that includes detailed information on candidate characteristics and their campaigns measured before the election. ${ }^{6}$ To measure candidates' political experience, we trace their political careers and code, at the time of the election, the number of times they had run for local council or any other office, and if they had ever held elected office. To measure other dimensions of candidate quality, we obtained information on voting registration from the electoral authority. We use these data to determine whether a candidate is registered to vote in the municipality s/he is seeking to represent, and whether the candidate has been illegally registered to vote in the past. ${ }^{7}$

\footnotetext{
${ }^{5}$ These register data contain missing information in 2003 for municipalities that had at least one closed list. We retrieved the original electoral ballots online and hand-coded the missing information.

${ }^{6}$ This is to make sure the characteristics observed are not a consequence of the election result and are therefore endogenous to list type.

${ }^{7}$ The main ways to register to vote illegally are to use a dead person's fingerprint, use a duplicate or fake ID, register to vote under the age of 18 , or to vote (illegally) in a municipality other than the one where the voter
} 
We also collect information on campaign expenditures and funds raised. The U.S. Agency for International Development, in collaboration with Transparency International and the National Democratic Institute, helped create a system for reporting all sources of campaign income and expenditures required under Resolution 1094. We leverage these data to classify campaign income by source. Personal funding sources include: contributions from the candidate or his/her immediate relatives; contributions from private donors; and financial credits in the candidate's name. Total funding sources include: state funding; party funding from public events; and party funding from private donors. ${ }^{8}$

We are interested in how the pre-election behavior of parties and candidates can explain the effects of list type on electoral outcomes. Hence, we analyze the pre-election open-list rankings set by the parties (instead of comparing post-election results determined by voters). For open list, the initial ranking may serve as an informative signal to voters of party preference; these rankings have been shown to affect vote counts in open-list elections (Miller and Krosnick, 1998). However, the initial rankings are obviously even more important for closed lists. Following Galasso and Nannicini (2015), we categorize these rankings into three groups: top (first ranked), marginal (second and third ranked), and bottom ranked (4+ ranked). ${ }^{9}$ This grouping is based on the likelihood of getting elected depending on the initial position on the list. Appendix Table A8) shows clear jumps in the likelihood of getting elected when comparing first and second, and third and fourth ranks, but no jumps at other list positions. In the robustness section, we show that all results are robust to alternative definitions of top, is registered. The latter is the most common form of election fraud, typically in exchange for small bribes.

${ }^{8}$ There are binding campaign fundraising/spending limits conditional on the number of registered voters in the municipality. For example, in a district with under 25,000 registered voters, the limit is 58 M COP (about $18^{\prime} 000$ USD). If a candidate spends more than the allowed amount, the sanctions range from a fine to returning the money to the state. In order to adjust campaign spending by the size of the constituency, we divide the absolute monetary amount by the corresponding limits. In 2011 the campaign limits were set at the individual level, but for 2015 they were established at the list level. To make these amounts comparable, we divide the total campaign limit per list by the number of candidates on each list. Potential effects of the change in the law should be absorbed by the election year fixed effects.

${ }^{9}$ Galasso and Nannicini (2015) argue that in closed lists, expressive or naive voters only care about the topranked candidates, whereas rational voters understand that they can only influence the election of marginal candidates on the lists, and thus focus their attention on those. 
marginal and bottom-ranked candidates.

For auxiliary analyses, we also obtained a panel dataset covering a broad range of economic, social and institutional characteristics at the municipality-level for the years 1993-2014 from the Center for Studies of Economic Development at the Universidad de los Andes Colombia. A detailed description of these variables is available in Appendix Table A11.

Tables A2 and A3 display the variation in ballot structure across parties and municipalities. We see that open lists are the far more popular choice, and that the share of municipalities in which at least one party used a closed list decreased from $40 \%$ in 2003 to $19 \%$ in 2007, but increased again to $27 \%$ in 2011 and to $45 \%$ in 2015. Nevertheless, this variation in list type is more than sufficient to identify its effects solely from within-party, within-municipality changes across election cycles.

Table A9 provides descriptive statistics for our main electoral outcomes. Most parties are fairly small: the average vote share for the party is only $13 \%$ and about $30 \%$ of parties do not obtain any seats. In this descriptive comparison of open and closed lists, parties running on open lists attract more votes, seats and candidates, and their candidates raise and contribute more campaign funds. We also see that candidates running on open lists have more political experience and are less likely to have a record of illegal voting and voting in a municipality other than the one where they are registered. In the next section, we detail the empirical strategy to assess whether these differences between open and closed list also persist once we control for party, municipality, and election year fixed effects.

\section{Empirical Strategy}

To estimate the effect of list type, we regress our indicators of electoral performance, the party's vote and seat shares, on a binary indicator for open list, and a full set of election year 
and municipality times party fixed effects, as shown in equation 1:

$$
y_{i p t}=\beta_{0}+\beta_{1} \text { OpenList }_{i p t}+\alpha_{i} \times \rho_{p}+\tau_{t}+\varepsilon_{i p t}
$$

Where $y_{\text {ipt }}$ is the electoral outcome in municipality $i$ for party $p$ in election period $t$; OpenList $t_{i p t}$ is a dummy that indicates if the party used an open-list ballot in municipality $i$ in election $t$; and $\alpha_{i}$ are the fixed effects for the municipalities, $\rho_{p}$ for the parties, and $\tau_{t}$ for the election years, respectively. The standard errors $\varepsilon_{i p t}$ are clustered at the municipal level. We use equivalent specifications to investigate the consequences of list type on other outcomes.

This two-way fixed effects model identifies the effect of list type, $\beta_{1}$, from parties that change from closed to open lists (or vice versa) in the same municipality from one election to the next, while the party crossed with municipality fixed effects control for all time-invariant differences between local parties and municipalities. As we discuss in detail below, almost all of the identifying variation comes from closed-list parties switching to open list, while switches in the other direction are exceedingly rare. While such an analysis might not completely address the partially endogenous choice of ballot type, it does rule out a large set of confounders that are typically present in cross-sectional comparisons. Furthermore, the following sections provide a variety of robustness tests and additional analyses that suggest that our results are unlikely to be driven by confounders or reverse causality.

\section{WhAT IS THE EFFECT OF OPEN/CLOSED LISTS ON PARTIES' ELECTORAL SUCCESS?}

Table 1 presents the results of estimating equation 1. The $\beta_{1}$ coefficients on the OpenList indicator in Models 1 and 2 reveal that switching from closed to open list increases a party's vote share by 4.9 percentage points and its seat share by 5.5 percentage points, which corresponds to a $64 \%$ and $75 \%$ increase, respectively, at the average. Adopting open list also decreases the probability of winning no council seats by 20 percentage points, a $51 \%$ decrease at the average. This suggests that running on a closed list is a risky strategy even for top-ranked candidates 
(typically the party leader), who might be willing to sacrifice additional seats for more party control as long as they are elected. All effects are substantively large and highly statistically significant.

\section{Table 1: Effect of open lists on electoral outcomes}

\begin{tabular}{rccc}
\hline \hline & $(1)$ & $(2)$ & $(3)$ \\
& Party vote share & Party seat share & Party one seat \\
\hline Open list & $0.049^{* * *}$ & $0.055^{* * *}$ & $0.199^{* * *}$ \\
& $(0.004)$ & $(0.005)$ & $(0.021)$ \\
Year dummies & $\checkmark$ & & $\checkmark$ \\
Mun FE x Party FE & $\checkmark$ & $\checkmark$ & $\checkmark$ \\
Mean dep. var & 0.077 & $\checkmark$ & \\
Effect size ( $\Delta$ \%) & 63.9 & 0.073 & 0.392 \\
$95 \%$ CI LB & 53.7 & 75.4 & 50.8 \\
$95 \%$ CI UB & 74.2 & 60.8 & 40.5 \\
Municipalities & 1101 & 90.1 & 61.0 \\
Observations & 18369 & 1101 & 1101 \\
\hline \hline
\end{tabular}

Notes: Standard errors are shown in parenthesis and are clustered at the municipality level. *** denotes statistical significance at the $1 \%$ level, ${ }^{* *} 5 \%$ level, and $* 10 \%$ level. The unit of analysis is a party in a municipality in an election.

We conduct several robustness checks to gauge the sensitivity of our main results. First, since we identify the effect mainly from parties that switch from closed to open list, these parties tend to be more experienced after the switch. This could confound our estimates if electoral success is due to parties having more experience in Colombia's volatile political landscape, rather than due to the effect of ballot type. A related concern arises if new parties are more likely to switch from closed to open list and are simultaneously more likely to increase their vote share in subsequent elections. To adjust for these differences in experience, we include a control variable that indicates the number of elections in which the party has participated in the same municipality. Appendix Table A12 shows that all results are robust to controlling for experience.

A second concern is that parties that switch from closed to open list are on different growth trajectories compared to parties that do not switch. To account for this possibility, Appendix 
Tables A18 and A20 show our main estimates controlling for party vote share in the previous election and for party-specific linear time trends, respectively. We find that all results are robust to controlling for past election results and party-specific linear time trends.

A potential third concern is whether most of our electoral results are driven by a single large party. Given that a total of 577 local parties switched between list type during the study period (see Appendix Table A7), we believe that this is unlikely to be an issue. Furthermore, we gauge the sensitivity of our findings by re-estimating equation 1 but iteratively dropping each of the main parties. Appendix Table A17 reports the results, and shows that the estimates remain very stable and always highly statistically significant across all models. Taken together, these tests corroborate the robustness of our main result that using open rather than closed list has a large effect on electoral performance.

Appendix Table A30 reports additional municipality-level regressions to determine whether the overall share of closed lists in a municipality influences aggregate electoral outcomes. While we find that the percentage of unmarked (blank) votes slightly increases with the share of closed lists, the point estimates for invalid votes and turnout are precisely estimated zeros. The latter

result is consistent with the hypothesis that parties compete over an approximately fixed pool of voters who are willing to change party allegiance based on list type. This finding also holds when we replace the share of closed lists with a binary indicator that takes on value one if at least one party fields a closed-list ballot in the municipality.

\section{Why Do Parties Fare Better with Open List?}

The analysis in the preceding section provides clear evidence that switching from closed to open list dramatically improves parties' electoral success. What mechanisms might explain this effect? Precise mechanisms are notoriously difficult to isolate using observational (and even experimental) data (Imai et al., 2011). Nonetheless, the following section aims to shed light on the importance of three main mechanisms: how list type conditions i) the incentives that 
candidates face to expend campaign effort, and the ii) quality and iii) number of candidates that parties can attract. For this, we draw on both qualitative and quantitative evidence. The qualitative insights are based on semi-structured interviews with 32 politicians from a representative sample of municipalities. In particular, we interviewed candidates for municipal councils from January to March 2016 about the elections that took place in October 2015. Appendix Section VIII provides a detailed description of the sampling strategy, questionnaire, and findings from these interviews.

The first mechanism that we explore postulates that open lists incentivize all candidates to campaign, while candidates at the bottom of closed lists are not motivated to campaign (see e.g., Shugart et al., 2005; Bergman et al., 2013; Nemoto and Shugart, 2013). What empirical evidence would support this mechanism? First, if this incentive mechanism is important, we would expect party officials and candidates to mention it in the qualitative interviews. This is indeed the case. For example, an unelected candidate on a closed list stated:

"[A] disadvantage [of closed lists] is that people lower on the list know that they won't make it, then they don't work as hard as people higher on the list. When the list is open one depends [more] upon oneself."

Candidate for the Cambio Radical Party in Entrerrios, Antioquia.

Similarly, an elected open-list candidate criticized closed lists for making it difficult to appropriate campaign effort, since the additional votes would go to the top of the list and there is little recognition of the effort made by other candidates:

"With open lists, each candidate works, and reaps what he sows; with closed lists you work for another person, it is not fair."

Candidate for the Partido de la U Party in Tamara, Casanare.

Second, we would expect candidates on closed lists to expend, on average, less campaign effort, and that this behavior is particularly pronounced among lower-ranked candidates, who 
have little chance of winning a seat. To test for this incentive mechanism, we replicate our twoway fixed effect model using candidate-level information on campaign effort as the outcome. As discussed in Section III in detail, our two-pronged measure of campaign effort counts the amount of personal funds a candidate contributes, and the total amount of funds a candidate raises. Table 2 shows the results. For both measures of campaign effort, Models 1 and 5 show that on average, when a closed-list party switches to an open list, campaign contributions increase by $57 \%$ for personal and $42 \%$ for total funds. Both estimates are substantial in size and highly statistically significant. Consistent with the hypothesis that candidates with a small chance of being elected have few incentives to expend effort, we find that these results are mostly driven by marginal and bottom-ranked candidates. The differences between topranked and marginal, and between top- and bottom-ranked candidates, respectively, are also statistically significant.

Table 2: Effect of open list on campaign investment

\begin{tabular}{|c|c|c|c|c|c|c|c|c|}
\hline & (1) & $(2)$ & $(3)$ & $(4)$ & $(5)$ & $(6)$ & $(7)$ & $(8)$ \\
\hline & \multicolumn{4}{|c|}{$\%$ of Campaign limit (Personal investment) } & \multicolumn{4}{|c|}{$\%$ of Campaign limit (Total investment) } \\
\hline & Average & Top & Marginal & Bottom & Average & Top & Marginal & Bottom \\
\hline Open list & $\begin{array}{c}0.016^{* * *} \\
(0.004)\end{array}$ & $\begin{array}{c}0.007 \\
(0.008)\end{array}$ & $\begin{array}{c}0.022^{* * *} \\
(0.005)\end{array}$ & $\begin{array}{c}0.018^{* * *} \\
(0.006)\end{array}$ & $\begin{array}{c}0.016^{* * *} \\
(0.004)\end{array}$ & $\begin{array}{c}-0.001 \\
(0.010)\end{array}$ & $\begin{array}{c}0.021^{* * *} \\
(0.005)\end{array}$ & $\begin{array}{c}0.024^{* * *} \\
(0.006)\end{array}$ \\
\hline Year dummies & $\checkmark$ & $\checkmark$ & $\checkmark$ & $\checkmark$ & $\checkmark$ & $\checkmark$ & $\checkmark$ & $\checkmark$ \\
\hline Mun FE x Party FE & $\checkmark$ & $\checkmark$ & $\checkmark$ & $\checkmark$ & $\checkmark$ & $\checkmark$ & $\checkmark$ & $\checkmark$ \\
\hline Mean dep. var & 0.028 & 0.039 & 0.029 & 0.027 & 0.039 & 0.080 & 0.040 & 0.034 \\
\hline Effect size $(\Delta \%)$ & 57.2 & 18.1 & 74.9 & 66.0 & 42.2 & -1.3 & 53.6 & 69.0 \\
\hline $95 \%$ CI LB & 29.8 & -23.3 & 42.1 & 26.3 & 19.6 & -26.9 & 26.9 & 35.0 \\
\hline $95 \%$ CI UB & 84.6 & 59.5 & 107.7 & 105.7 & 64.7 & 24.3 & 80.4 & 103.0 \\
\hline Municipalities & 1072 & 1022 & 1043 & 1058 & 1072 & 1022 & 1044 & 1058 \\
\hline Observations & 8668 & 6487 & 7149 & 7942 & 8674 & 6497 & 7159 & 7958 \\
\hline
\end{tabular}

Notes: Standard errors are shown in parenthesis and are clustered at the municipality level. *** denotes statistical significance at the $1 \%$ level, ${ }^{*} 5 \%$ level, and * $10 \%$ level. The unit of analysis is a party in a municipality in an election. "Top" are candidates located at the top of the list, "marginal" candidates are located in the second and third position, and "bottom" are candidates listed fourth to last (measured before the election).

The second mechanism postulates that because closed lists do not reward politicians' individual campaign efforts and lower the chances of winning a seat, they fail to attract high-quality 
candidates. We also find qualitative and quantitative evidence for this selection mechanism. Indeed, this mechanism was brought up many times by our interviewees. When asked about how the party selects the candidates at the bottom of the closed list, the interviews revealed that these are often people affiliated with the party who have little formal education or political knowledge, and no interest in holding office. For example, a sixth-placed candidate on a closed list with no chance of winning said:

"I don't understand the difference between open and closed lists, I was just supporting our candidate (top of the list) who didn't get elected..."

Candidate for the Partido de la U Party in Paez, Cauca.

Similarly, we interviewed an indigenous person who was never engaged in politics before but who was apparently lured into signing the paperwork to run as a candidate on a closed list, without properly understanding the implications of it. It appears that in this case, the party's sole goal was to simply fill the list. Another lower-placed, closed-list candidate mentioned that parties sometimes "trick" people who enjoy some local popularity, but have limited political knowledge, to run as low-ranked candidates on closed lists to garner votes for the top candidate:

"In this municipality people take advantage of others, of the peasants, honest people who want to work. (...) Sometimes a popular person who has support in his district but doesn't know much about politics is placed low on the closed list, so the people placed high on the list win those votes without doing anything."

Candidate for the Partido de la U Party in Tamara, Casanare.

We again leverage our candidate-level data to quantitatively test whether closed lists struggle to attract high quality candidates. In particular, we test whether candidates on open lists have more political experience, measured as the number of times the candidates have run in previous municipal elections, the number of times they have been elected to the municipal 
council, and the number of times they have participated in any other election. Models 1, 5, and 11 in Table 3 report the results. We find that on average, open lists are able to attract significantly more experienced candidates. Models 2-4, 6-8 and 12-14 show that this effect arises solely from the bottom-ranked positions for all three experience measures, with effect sizes ranging from 10\%-15\% for running in previous elections to $95 \%$ for having previously served in office.

Table 3: Effect of open list on political experience

\begin{tabular}{|c|c|c|c|c|c|c|c|c|}
\hline & $(1)$ & $(2)$ & $(3)$ & $(4)$ & $(5)$ & $(6)$ & $(7)$ & $(8)$ \\
\hline & \multicolumn{4}{|c|}{ \# of times cand. ran any post } & \multicolumn{4}{|c|}{ \# of times cand. ran council } \\
\hline & Average & Top & Marginal & Bottom & Average & Top & Marginal & Bottom \\
\hline Open list & $\begin{array}{c}0.081^{* * *} \\
(0.026)\end{array}$ & $\begin{array}{c}0.008 \\
(0.053)\end{array}$ & $\begin{array}{c}0.055 \\
(0.040)\end{array}$ & $\begin{array}{c}0.243^{* * *} \\
(0.028)\end{array}$ & $\begin{array}{l}0.036^{*} \\
(0.019)\end{array}$ & $\begin{array}{c}0.000 \\
(0.044)\end{array}$ & $\begin{array}{c}0.030 \\
(0.032)\end{array}$ & $\begin{array}{c}0.141^{* * *} \\
(0.023)\end{array}$ \\
\hline Year dummies & $\checkmark$ & $\checkmark$ & $\checkmark$ & $\checkmark$ & $\checkmark$ & $\checkmark$ & $\checkmark$ & $\checkmark$ \\
\hline Mun FE x Party FE & $\checkmark$ & $\checkmark$ & $\checkmark$ & $\checkmark$ & $\checkmark$ & $\checkmark$ & $\checkmark$ & $\checkmark$ \\
\hline Mean dep. var & 1.715 & 2.130 & 1.777 & 1.569 & 1.521 & 1.814 & 1.573 & 1.408 \\
\hline Effect size $(\Delta \%)$ & 4.7 & 0.4 & 3.1 & 15.5 & 2.4 & 0.0 & 1.9 & 10.0 \\
\hline $95 \%$ CI LB & 1.7 & -4.4 & -1.3 & 12.0 & -0.1 & -4.7 & -2.1 & 6.9 \\
\hline $95 \%$ CI UB & 7.7 & 5.2 & 7.5 & 19.0 & 4.8 & 4.7 & 6.0 & 13.2 \\
\hline Municipalities & 1101 & 1101 & 1101 & 1101 & 1101 & 1101 & 1101 & 1101 \\
\hline \multirow[t]{4}{*}{ Observations } & 18365 & 18206 & 18091 & 17165 & 18365 & 18206 & 18091 & 17165 \\
\hline & $(11)$ & $(12)$ & $(13)$ & $(14)$ & & & & \\
\hline & \multicolumn{4}{|c|}{ \# of times cand. was councilor } & & & & \\
\hline & Average & Top & Marginal & Bottom & & & & \\
\hline Open list & $\begin{array}{c}0.058^{* * *} \\
(0.012)\end{array}$ & $\begin{array}{c}-0.085^{* *} \\
(0.036)\end{array}$ & $\begin{array}{c}0.033 \\
(0.022)\end{array}$ & $\begin{array}{c}0.128^{* * *} \\
(0.014)\end{array}$ & & & & \\
\hline Year dummies & $\checkmark$ & $\checkmark$ & $\checkmark$ & $\checkmark$ & & & & \\
\hline Mun FE x Party FE & $\checkmark$ & $\checkmark$ & $\checkmark$ & $\checkmark$ & & & & \\
\hline Mean dep. var & 0.194 & 0.507 & 0.235 & 0.135 & & & & \\
\hline Effect size $(\Delta \%)$ & 29.8 & -16.8 & 14.1 & 94.8 & & & & \\
\hline $95 \%$ CI LB & 18.0 & -30.7 & -4.7 & 75.2 & & & & \\
\hline $95 \%$ CI UB & 41.5 & -2.8 & 32.8 & 114.5 & & & & \\
\hline Municipalities & 1101 & 1101 & 1101 & 1101 & & & & \\
\hline Observations & 18365 & 18206 & 18091 & 17165 & & & & \\
\hline
\end{tabular}

Notes: Standard errors are shown in parenthesis and are clustered at the municipality level. *** denotes statistical significance at the $1 \%$ level, ** $5 \%$ level, and * $10 \%$ level. The unit of analysis is a party in a municipality in an election. "Top" are candidates located at the top of the list, "marginal" candidates are located in the second and third position, and "bottom" are candidates listed fourth to last (measured before the election). 
As a second measure of candidate quality, we focus on the candidate's dedication to and engagement in the municipality they seek to represent by measuring whether he/she registered to vote in this municipality before the election. Table 4 shows the results. While an overwhelming majority of candidates on both open and closed lists is indeed registered in the municipality where they are running, open-list candidates are about $5 \%$ more likely to do so, a statistically significant effect. For this measure, we do not find significant differences in the effect estimates between different list positions.

Table 4: Effect of open list type on engagement in constituency

\begin{tabular}{lcccc}
\hline \hline & $(1)$ & $(2)$ & $(3)$ & $(4)$ \\
& Average & Top & Marginal & Bottom \\
\hline Open list & & & & \\
& $0.042^{* * *}$ & $0.071^{* * *}$ & $0.037^{* * *}$ & $0.037^{* * *}$ \\
& $(0.009)$ & $(0.018)$ & $(0.014)$ & $(0.012)$ \\
Year dummies & & & & \\
Mun FE x Party FE & $\checkmark$ & $\checkmark$ & $\checkmark$ & $\checkmark$ \\
& & $\checkmark$ & $\checkmark$ & $\checkmark$ \\
Mean dep. var & 0.897 & 0.889 & 0.905 & 0.902 \\
Effect size ( $\Delta$ \%) & 4.7 & 8.0 & 4.1 & 4.1 \\
95\% CI LB & 2.6 & 4.1 & 1.1 & 1.4 \\
95\% CI UB & 6.7 & 12.0 & 7 & 6.8 \\
Municipalities & 1101 & 1101 & 1101 & 1101 \\
Observations & 18333 & 16944 & 17910 & 17094 \\
\hline \hline
\end{tabular}

Notes: Standard errors are shown in parenthesis and are clustered at the municipality level. *** denotes statistical significance at the $1 \%$ level, ${ }^{* *} 5 \%$ level, and * $10 \%$ level. The unit of analysis is a party in a municipality in an election. "Top" are candidates located at the top of the list, "marginal" candidates are located in the second and third position, and "bottom" are candidates listed fourth to last (measured before the election).

As a third measure of candidate quality, we focus on two indicators of fraudulent voting behavior. We code whether the candidates are registered to vote illegally, or illegally moved to a different polling station than where they were registered before the election. Again, these are pre-treatment variables, measuring fraudulent behavior in previous elections. Table 5 shows the results. While only a small minority of candidates engaged in election fraud, we find that on average, open-list candidates are $28 \%$ less likely to have registered to vote illegally, and $33 \%$ less likely to have voted in a polling station without registering. The differences in the 
effect estimates across list positions are minor.

Table 5: Effect of open list on election fraud

\begin{tabular}{|c|c|c|c|c|c|c|c|c|}
\hline & (1) & $(2)$ & $(3)$ & $(4)$ & $(5)$ & $(6)$ & $(7)$ & $(8)$ \\
\hline & \multicolumn{4}{|c|}{ Registered illegally to vote } & \multicolumn{4}{|c|}{ Voted illegally in different polling station } \\
\hline & Average & Top & Marginal & Bottom & Average & Top & Marginal & Bottom \\
\hline Open list & $\begin{array}{c}-0.013^{* *} \\
(0.005)\end{array}$ & $\begin{array}{l}-0.016 \\
(0.012)\end{array}$ & $\begin{array}{c}-0.021^{* *} \\
(0.009)\end{array}$ & $\begin{array}{c}-0.018^{* *} \\
(0.008)\end{array}$ & $\begin{array}{c}-0.014^{* * *} \\
(0.005)\end{array}$ & $\begin{array}{c}-0.021^{*} \\
(0.011)\end{array}$ & $\begin{array}{c}-0.022^{* *} \\
(0.009)\end{array}$ & $\begin{array}{c}-0.017 * * \\
(0.008)\end{array}$ \\
\hline Year dummies & $\checkmark$ & $\checkmark$ & $\checkmark$ & $\checkmark$ & $\checkmark$ & $\checkmark$ & $\checkmark$ & $\checkmark$ \\
\hline Mun FE x Party FE & $\checkmark$ & $\checkmark$ & $\checkmark$ & $\checkmark$ & $\checkmark$ & $\checkmark$ & $\checkmark$ & $\checkmark$ \\
\hline Mean dep. var & 0.045 & 0.048 & 0.041 & 0.046 & 0.043 & 0.042 & 0.039 & 0.044 \\
\hline Effect size $(\Delta \%)$ & -27.8 & -34.5 & -50.1 & -38.4 & -33.4 & -49.9 & -56.5 & -38.1 \\
\hline $95 \%$ CI LB & -49.1 & -81.8 & -92.2 & -72.4 & -55.5 & -101.5 & -99.7 & -73.2 \\
\hline $95 \%$ CI UB & -6.5 & 12.8 & -8.0 & -4.4 & -11.3 & 1.6 & -13.3 & -3.0 \\
\hline Municipalities & 1101 & 1101 & 1101 & 1101 & 1101 & 1101 & 1101 & 1101 \\
\hline Observations & 18365 & 18201 & 18091 & 17165 & 18365 & 18201 & 18091 & 17165 \\
\hline
\end{tabular}

Notes: Standard errors are shown in parenthesis and are clustered at the municipality level. *** denotes statistical significance at the $1 \%$ level, ** $5 \%$ level, and * $10 \%$ level. The unit of analysis is a party in a municipality in an election. "Top" are candidates located at the top of the list, "marginal" candidates are located in the second and third position, and "bottom" are candidates listed fourth to last (measured before the election).

In exploring the first two mechanisms, we have shown that open lists increase the quality and campaign effort of candidates. But are these candidate characteristics and behaviors actually valued by voters? To answer this question, we compare the initial ranking of open-list candidates (by the party) to the post-election ranking (by the voters) to investigate which candidate qualities matter most to voters. For this, we compare the share of candidates who moved up, down, or did not change their list positions, separately for candidates with and without desirable qualities. Appendix Table A31 shows the results. In line with our expectations, we find clear evidence that candidates' personal and total campaign investments, our proxy for campaign effort, significantly increase their chances of moving up the list. Both measures of past fraudulent voting behaviour have a negative effect on the final list rank. Lastly, political experience in the form of previous runs for public office (any) or council (specific) increases the chances of moving up the list, as does previous experience as a councillor. All changes in list positions are politically meaningful (the differences in the share of candidates 
that move up the list range between $6 \%$ and $28 \%$ depending on the quality measure) and highly statistically significant. In sum, we find strong evidence that open lists offer voters the chance to select candidates who exhibit qualities they value.

The third mechanism that we explore postulates that open lists simply attract more candidates than closed lists, because, as several interviewees suggested, "[on open lists,] every candidate has a fair chance of winning". To assess this mechanism, we explore the effect of list type on the number of candidates and the total of campaign contributions raised by all candidates on the list. Table 6 reports our estimates, and shows that switching to open list increases the number of candidates on the list by $18 \%$ and the total campaign effort by $55 \%$. Both effects are precisely estimated and highly significant.

Table 6: Effect of open lists on campaign spending and list positions filled

\begin{tabular}{rcc}
\hline \hline & $(1)$ & $(2)$ \\
& Total campaign effort by party & $\%$ of list filled \\
\hline Open list & $0.044^{* * *}$ & $0.113^{* * *}$ \\
& $(0.010)$ & $(0.014)$ \\
Year dummies & & $\checkmark$ \\
Mun FE (x) Party FE & $\checkmark$ & $\checkmark$ \\
Mean dep. var & $\checkmark$ & \\
Effect size ( $\Delta$ \%) & 0.079 & 17.8 \\
$95 \%$ CI LB & 55.5 & 13.5 \\
$95 \%$ CI UB & 31.5 & 22.2 \\
Municipalities & 79.5 & 1101 \\
Observations & 1072 & 18351 \\
\hline \hline
\end{tabular}

Notes: Standard errors are shown in parenthesis and are clustered at the municipality level. *** denotes statistical significance at the $1 \%$ level, $* * 5 \%$ level, and $* 10 \%$ level. The unit of analysis is a party in a municipality in an election. In 2011 , campaign limits were set at the individual level, but for 2015 they were established at the list level. To make these amounts comparable, we divide the total campaign limit per list by the number of candidates on each list for the outcome of Model (1). Model (2) uses the number of candidates, relative to the maximum size of the list, as outcome.

To summarize our qualitative and quantitative evidence in support of the three mechanism, we find that: Open lists create incentives for all candidates to expend more effort campaigning, attract higher quality candidates that are more experienced, more committed to their constituency, and less likely to have voted illegally in the past, and allow parties to list more 
candidates overall.

To assess the robustness of these findings, we conduct a variety of additional tests. First, all results for campaign effort (see Table A13) and candidate quality (see Tables A14, A15, and A16) are robust to controlling for the number of municipal elections in which the local party has participated in. ${ }^{10}$ Second, the estimates on campaigning, candidate experience and other candidate quality measures all hold after controlling for their party's previous vote shares (see Table A21) as well as party-specific linear time trends (see Table A19), with the point estimates being very similar across specifications. Third, we again gauge the sensitivity of our estimates by iteratively dropping each of the main parties to assess whether our estimates are driven by a single large party. Table A17 in the Appendix reports the results, and shows that the estimates remain very stable and always highly statistically significant. Fourth, we employ an alternative coding for top, marginal and bottom candidates. Tables A22, A23, A24, and A25 show the results when coding the second-ranked initial list position as marginal. Tables A26, A27, A28, and A29 show the results when coding the second, third, and fourth positions as marginal. The main findings are not affected by these different codings. Together, these tests corroborate the robustness of the results to different model specifications.

Lastly, one might worry that most of the effects we document here are driven by reverse causality. This would mean that is not the local parties, which select higher-quality candidates through the adoption of open list, but rather higher-quality candidates banding together and deciding that they want to run on open list (and low-quality candidates choosing closed list). Fortunately, our qualitative and quantitative data can speak to the plausibility of this alternative explanation. First, the evidence presented above on the differences in candidate quality in top, marginal, and bottom closed-list positions is hard to reconcile with the idea that low quality candidates would choose to adopt closed list, just to put themselves at the bottom

\footnotetext{
${ }^{10}$ One explanation of why party experience does not moderate our results is Colombia's fairly candidatecentered system; according to our interviews, parties simply provide their credentials for candidates to run, which weakens parties' institutional memory.
} 
of the list. Second, in several qualitative interviews, the candidates emphasized the struggle that parties running on closed lists face in attracting high-quality candidates, especially for low-ranked positions. For example, one candidate said:

"I wouldn't support closed lists, because it promotes corruption, you put lower people on the list to work for the top. (...) I say corruption because the top of the list convinces popular peasants, who are clueless, to be part of a closed list and thereby get votes for themselves"

\section{Candidate for the Green Party in Liborina, Antioquia}

and another candidate mentioned:

"Closed lists are undemocratic because they elect the first-placed on the list, and there is no equality in conditions (...) the ones at the bottom of the list are fillers because it is very unlikely that they will be elected"

\section{Candidate for the Radical Change parte in Arauca, Aruaca}

Thus, the interviews suggest that lower-ranked candidates on closed lists had little, if any, say about the choice of list type - a decision that is tupically made by the local party leader. Third, we can test the hypothesis of reverse causality by controlling for candidate fixed effects - and thereby holding candidate quality constant - in candidate-level regressions of election success on ballot structure. ${ }^{11}$ In essence, this allows us to estimate the effect of list type on the probability of getting elected for the same candidate. If our effects are solely driven by reverse causality, i.e. higher quality of candidates choosing to run on open list (and low-quality candidates on closed list), the coefficient on list type would be zero once we control for (time-constant) candidate quality using candidate fixed effects. To test for this, we regress

\footnotetext{
${ }^{11}$ We cannot conduct these candidate fixed effects regression for other candidate-level outcomes such as experience or fraudulent voting behavior because they are measured pre-treatment and are therefor not timevarying.
} 
an indicator for getting elected to office on candidate times party fixed effects, election and municipality fixed effects, and a binary indicator that takes on value one if the candidate runs on a list that switched from closed to open in consecutive elections. We estimate this regression for all consecutive elections (i.e. the 2003/2007, 2007/2011, and 2011/2015 election pairs). Models $1-3$ in Table 7 show the results.

Table 7: Effect of switching from closed to open list on election probability

\begin{tabular}{|c|c|c|c|}
\hline \multirow[b]{3}{*}{ Period: } & \multirow{2}{*}{\multicolumn{3}{|c|}{$\begin{array}{l}(1) \\
\text { Elected in Current Election }\end{array}$}} \\
\hline & & & \\
\hline & $2003 / 2007$ & $2007 / 2011$ & $2011 / 2015$ \\
\hline Switch Closed to Open & $\begin{array}{c}0.254^{* * *} \\
(0.057)\end{array}$ & $\begin{array}{c}0.362^{* * *} \\
(0.061)\end{array}$ & $\begin{array}{c}0.149^{* * *} \\
(0.043)\end{array}$ \\
\hline Cand FE x Party FE & $\checkmark$ & $\checkmark$ & $\checkmark$ \\
\hline Year FE & $\checkmark$ & $\checkmark$ & $\checkmark$ \\
\hline Mun FE & $\checkmark$ & $\checkmark$ & $\checkmark$ \\
\hline Mean dep. var & 0.483 & 0.461 & 0.466 \\
\hline Effect size $(\Delta \%)$ & 52.7 & 78.5 & 32.0 \\
\hline $95 \%$ CI LB & 29.7 & 52.6 & 14.0 \\
\hline $95 \%$ CI UB & 75.7 & 104.5 & 50.1 \\
\hline Municipalities & 896 & 1060 & 1092 \\
\hline Observations & 7818 & 14536 & 21300 \\
\hline
\end{tabular}

Notes: Standard errors are shown in parenthesis and are clustered at the municipality level. *** denotes statistical significance at the $1 \%$ level, ${ }^{* *} 5 \%$ level, and $* 10 \%$ level. The unit of analysis is a party in a municipality in an election. "Top" are candidates located at the top of the list, "marginal" candidates are located in the second and third position, and "bottom" are candidates listed fourth to last (measured before the election). Sample consists of candidates who run open lists in two electoral periods (Switch Closed to Open $=0$ ), and candidates who switched from closed to open lists (Switch Closed to Open $=0$ ).

We consistently find strong and positive effects: depending on the election year, the probability of getting elected increases between $32 \%$ and $78 \%$ for the same candidate, running for the same party, when the ballot type is switching from closed to open. For all election cycles, these effects are highly statistically significant. Together, the three pieces of evidence suggest that reverse causality is unlikely to be a main driver of our findings on the electoral benefits of open list. 


\section{Why Do Some Parties Sometimes Choose Closed List?}

Given their detrimental impact on electoral performance, one has to wonder why some parties decide to field closed list. One hypothesis is that closed-list parties can exert more control over their candidates and who gets elected. Indeed, the president of a local party frankly admitted as much:

"With closed lists the party has more control over candidates, and I as president could control the candidates more, while with open lists they are autonomous."

Candidate for Polo Democrático Alternativo in Balboa, Cauca.

Several interviewees also noted that closed lists induce and signal party cohesion. For example, one candidate explained the benefits of closed lists for ideological cohesion:

"When the list is closed the party is strengthened institutionally, because you are voting for a party and not a person, and this could lead to more ideological party cohesion."

Candidate for the Alianza Verde Party in Cartago, Valle.

Another thought the signal it sends is more important:

"We were a group of friends interested in the welfare of the municipality (...) we chose closed list because we thought it was the best way to present ourselves to the community, as a group, a family, rather than a party with people who each walked their own path. The idea is that the community would see us as a team (...)"

Candidate for the Polo Party in Pasto, Nariño.

But even after accounting for the benefits of closed list for party control and cohesion, one might wonder if running with closed list is a viable long-term strategy. Given their massive, 
detrimental effect on vote and seat shares, we might expect that after choosing closed list in an election, and suffering the associated electoral losses, most parties would switch to open list in the next election cycle. To assess this hypothesis, the transition matrix presented in Table 8 explores the dynamics of switching between ballot structures. Indeed, we find that if a party uses a closed list in election $t$, the chances are very high that it switches to an open list in the next election $t+1$. Moreover, and not surprising given our main findings on the electoral losses associated with closed list, the unconditional transition matrix presented in Appendix Table A5 shows that closed-list parties are also less likely to run again in $t+1$. This suggests that open lists are an absorbing state, and that closed lists are mostly used by new parties.

Table 8: Transition Matrix.

\begin{tabular}{lcc}
\hline \hline & Closed List $t+1$ & Open List $t+1$ \\
Closed List $t$ & 0.26 & 0.74 \\
Open List $t$ & 0.02 & 0.98 \\
\hline \hline
\end{tabular}

Note: Transition matrix shows the share of parties that use open and closed lists in consecutive elections, and how they switch between list types. Estimates are conditional on parties running in consecutive elections $t$ and $t+1$.

In the Appendix, we explore this pattern in more detail. Table A6 shows that the ten major parties rarely use closed list, especially so in more recent elections. Among the major parties, only the new entrant in 2015, the Centro Democrático, decided to field closed lists in about $50 \%$ of the races. Table A10 provides further evidence that closed lists are mainly popular among new and small parties. The conditional and unconditional transition matrices presented in Tables A4 and A5 show that the pattern Table 8 documents for parties also applies to their candidates. Together, these findings strongly suggest that mostly new parties make the consequential decision to run on closed lists in their first election, but quickly learn (if they survive the election) based on direct voter feedback - but not from indirectly observing the experiences of other parties, or the same party in other municipalities, that made the same choice in the past. 


\section{Conclusions}

A large body of research argues that electoral systems shape policy and politics in important ways. While identifying the effects of electoral institutions is notoriously difficult (Snyder, 2001; Shugart, 2013), a nascent but growing literature leverages subnational and over-time variation in electoral institutions to study their effects. We contribute to this literature by establishing that ballot structures affect the behavior of votes, candidates and parties. We provide quantitative and qualitative evidence from Colombia, where parties are free to choose between open and closed lists in local PR elections. This provides rare within-municipality, within-party and over-time variation in list type, which we use to study its consequences for electoral performance and to shed light on the underlying mechanisms. Leveraging panel data covering the 1,100 Colombian municipalities for the 2003-2015 period, we find that parties that adopt open list benefit from dramatically higher vote and seat shares.

To understand the trade-offs parties face when deciding on the list type, we conducted extensive semi-structured interviews with a representative sample of candidates. Building on the insights from these interviews, we explore three mechanisms that connect ballot structures and electoral outcomes. First, the interviews reveal that lower-ranked closed-list candidates, who have a low probability of getting elected, expend less campaign effort than similarly ranked open-list candidates. Second, many interviewees mentioned that closed lists struggle to attract high-quality candidates for lower-ranked list positions whereas open-lists do not. Third, because open lists reward individual effort, they are able to attract a larger number of candidates. We provide quantitative support for those mechanisms by leveraging candidate-level panel data. We find that by adopting open lists, parties can incentivize all listed candidates to expend more campaign effort, can attract more - and more experienced-candidates, and can select candidates who are more committed to their constituency and less likely to have engaged in election fraud. We explore whether these results are driven by high-quality candidates choosing open- and low-quality candidates choosing closed lists, rather than ballot structure 
itself. In regressions pooling consecutive elections and controlling for candidate fixed effects, we show that switching from closed to open list dramatically increases the chances of getting elected for the same candidate, running for the same party and in the same municipality. Thus, our findings are unlikely to be accounted for by reverse causality.

Our study provides perhaps the most direct evidence to date that closed lists have negative consequences for parties and the quality of candidates when focusing on the same party and municipality in consecutive elections. With respect to the Colombian context, this suggests that if local parties were to exclusively move to open lists, we would expect elected politicians to be more experienced and more engaged. This finding supports previous studies that argue the direct link between individual performance and reappointment created by open lists incentivizes good governance (Persson et al., 2003). For the general study of electoral systems, our research design showcases the inferential advantages of leveraging over-time, subnational combined for identifying their consequences. The results emphasize the interplay between electoral systems and the preferences of parties, candidates, and voters in shaping political competition and selection.

How generalizable are our findings? The 2003 election reform in Colombia provides us with rare variation in list type that allows us to study its effects. However, this variation might also limit the external validity of our findings. A first question concerns how well our results would travel were another country to adopt a mixed-ballot system. For example, the Danish election law grants parties a similar choice between open and semi-open lists. While a variety of contextual factors including the number and strength of parties will moderate the relationship between list type and electoral outcomes (Shugart, 2013), we conjecture that the sign of the relationship would be the same in such context.

What can we infer from our estimates from Colombia's mixed-ballot system about the performance differences between a pure open-list and pure closed-list system? At this stage, we can only speculate on such inferences, among other things because in our study period, there 
are no elections in which all parties in a given municipality used closed lists. However, while the point estimates from a pure open- to closed-list comparison might well be different, we would expect that the incentives associated with different ballot structures that we document here would also apply in other contexts. In particular, we expect that in an exclusively closedlist system, parties will face similar difficulties in attracting high-quality candidates and in incentivizing them to campaign for lower-ranked list positions. While lower-ranked high-quality candidates in a closed-list system cannot switch to an open-list party as in Colombia, some of them will likely decide against running at all, thereby confronting parties with the same dilemma documented here. Both lines of reasoning about external validity suggest that the mechanisms connecting closed list to negative electoral consequences would also hold outside of the Colombian context. Nonetheless, we believe that external validity is best addressed not by conjectures, but by replicating internally valid studies in other countries.

Our study shows that the seemingly narrow difference between open and closed lists had major repercussions - not only for Colombian parties and politicians, but also the quality of representative democracy. Since the quality of political representation is an important determinant of public policies, we believe that exploring the downstream effects of ballot structures on policy outcomes is a particularly exciting avenue for further research. We hope that our research design, with its focus on subnational and temporal variation in election systems, will serve as a template for future studies. 


\section{REFERENCES}

Achury, S., M. Ramírez, and F. Cantú (2017). Endogenous ballot structures: The selection of open and closed lists in Colombia's legislative elections. Electoral Studies 49, 136-154.

Aghion, A. Alesina, and F. Trebbi (2004). Endogenous Political Institutions. Quarterly Journal of Economics 119, 565-611.

Aghion, P., A. Alesina, and F. Trebbi (2007). Democracy, Technology, and Growth. National Bureau of Economic Research (13180). DOI: 10.3386/w13180.

Ames, B. (1995). Electoral Strategy under Open-List Proportional Representation. American Journal of Political Science 39(2), 406-433.

Ashworth, S. and E. Bueno de Mesquita (2006). Delivering the Goods: Legislative Particularism in Different Electoral and Institutional Settings. Journal of Politics 68, 168-179.

Bechtel, M. M., D. Hangartner, and L. Schmid (2016). Does compulsory voting increase support for leftist policy? American Journal of Political Science 60(3), 752-767.

Bergman, M. E., M. S. Shugart, and K. A. Watt (2013). Patterns of intraparty competition in open-list \& SNTV systems. Electoral Studies 32(2), 321-333.

Besley, T. (2005). Political Selection. Journal of Economic Perspectives 19(3), 43-60.

Blais, A. and R. K. Carty (1990). Does proportional representation foster voter turnout? European Journal of Political Research 18(2), 167-181.

Blumenau, J., A. C. Eggers, D. Hangartner, and S. Hix (2017). Open/Closed List and Party Choice: Experimental Evidence from the UK. British Journal of Political Science 47(4), 809-827.

Braeuninger, T., T. Daeubler, R. Huber, and L. Rudolph (2019). The performance of populist right parties in open and closed list pr system. evidence from a survey experiment.

Buisseret, P. E. and C. Prato (2018). Competing Principals? Legislative Representation in List PR Systems. Social Science Research Network (ID 3007275).

Bushnell, D. (1993). The making of modern Colombia: a nation in spite of itself. Berkeley: 
University of California Press.

Carey, J. M. and M. S. Shugart (1995). Incentives to cultivate a personal vote: A rank ordering of electoral formulas. Electoral Studies 14(4), 417-439.

Chang, E. C. C. (2005). Electoral Incentives for Political Corruption under Open-List Proportional Representation. Journal of Politics 67(3), 716-730.

Chang, E. C. C. and M. A. Golden (2007). Electoral Systems, District Magnitude and Corruption. British Journal of Political Science 37(1), 115-137.

Cho, S.-J. (2014). Voting Equilibria Under Proportional Representation. American Political Science Review 108(2), 281-296.

Cox, G. and M. Shugart (1996). Strategic Voting Under Proportional Representation. Journal of Law, Economics and Organization 12, 299-324.

Crisp, B. F., M. C. Escobar-Lemmon, B. S. Jones, M. P. Jones, and M. M. Taylor-Robinson (2004). Vote-Seeking Incentives and Legislative Representation in Six Presidential Democracies. The Journal of Politics 66(3), 823-846.

Dal Bó, E., F. Finan, O. Folke, T. Persson, and J. Rickne (2017). Who Becomes a Politician? The Quarterly Journal of Economics 132, 1877--1914.

Dal Bó, E. and F. Finan (2018). Progress and perspectives in the study of political selection. Annual Review of Economics 10, 541-575.

Duverger, M. (1954). Political Parties: Their Organisation and Activity in the Modern State. Methuen; Wiley.

Eggers, A. C. (2015). Proportionality and turnout: Evidence from french municipalities. Comparative Political Studies 48(2), 135-167.

Fiva, J. H. and O. Folke (2016). Mechanical and psychological effects of electoral reform. British Journal of Political Science 46(2), 265-279.

Fowler, A. (2013). Electoral and policy consequences of voter turnout: Evidence from compulsory voting in australia. Quarterly Journal of Political Science 8(2), 159-182. 
Fujiwara, T. et al. (2011). A regression discontinuity test of strategic voting and duverger's law. Quarterly Journal of Political Science 6(3-4), 197-233.

Galasso, V. and T. Nannicini (2011). Competing on Good Politicians. American Political Science Review 105(1), 79-99.

Galasso, V. and T. Nannicini (2015). So closed: Political selection in proportional systems. European Journal of Political Economy 40(Part B), 260-273.

Grimmer, J., S. Messing, and S. J. Westwood (2012). How Words and Money Cultivate a Personal Vote: The Effect of Legislator Credit Claiming on Constituent Credit Allocation. American Political Science Review 106(4), 703-719.

Grofman, B. (2008). The Impact of Electoral Laws on Political Parties. The Oxford Handbook of Political Economy.

Hallerberg, M. and P. Marier (2004). Executive Authority, the Personal Vote, and Budget Discipline in Latin American and Caribbean Countries. American Journal of Political Science 48(3), 571-587.

Herrera, H., M. Morelli, and T. Palfrey (2014). Turnout and Power Sharing. The Economic Journal 124(574), F131-F162.

Hortala-Vallve, R. and H. Mueller (2015). Primaries: the unifying force. Public Choice 163(34), 289-305.

Hoyos, D. (2005). Evolución del sistema de partidos en Colombia 1972-2000. Una mirada local y regional. Análisis Político 18(55), 45-59.

Iaryczower, M. and A. Mattozzi (2013). On the Nature of Competition in Alternative Electoral Systems. The Journal of Politics 75(3), 743-756.

Imai, K., L. Keele, D. Tingley, and T. Yamamoto (2011). Unpacking the Black Box of Causality: Learning about Causal Mechanisms from Experimental and Observational Studies. American Political Science Review 105(4), 765-789.

Leemann, L. and I. Mares (2014). The Adoption of Proportional Representation. The Journal 
of Politics 76(2), 461-478.

Meyersson, E. (2014). Islamic rule and the empowerment of the poor and pious. Econometrica 82(1), 229-269.

Mill, J. S. (1861). Considerations on Representative Government. Cambridge Library Collection - British and Irish History, 19th Century. Cambridge University Press.

Miller, J. M. and J. A. Krosnick (1998). The Impact of Candidate Name Order on Election Outcomes. The Public Opinion Quarterly 62(3), 291-330.

Nemoto, K. and M. S. Shugart (2013). Localism and coordination under three different electoral systems: The national district of the Japanese House of Councillors. Electoral Studies 32(1), 1-12.

Norris, P. (2004). Electoral engineering: Voting rules and political behavior. Cambridge university press.

Pachón, M. and M. S. Shugart (2010). Electoral reform and the mirror image of inter-party and intra-party competition: The adoption of party lists in colombia. Electoral Studies 29(4), $648-660$.

Pachón, M. and F. Sánchez (2014). Base de datos sobre resultados electorales CEDE. 1958 a 2011. Documentos CEDE 2014-29(21), 1-30.

Persson, T., G. Tabellini, and F. Trebbi (2003). Electoral Rules and Corruption. Journal of the European Economic Association 1(4), 958-989.

Reynolds, A., B. Reilly, and A. Ellis (2008). Electoral system design: The new international IDEA handbook. International Institute for Democracy and Electoral Assistance.

Sanz, C. (2015). The Effect of Electoral Systems on Voter Turnout: Evidence from a Natural Experiment. Political Science Research and Methods, 1-22.

Serra, G. (2011). Why primaries? The party's tradeoff between policy and valence. Journal of Theoretical Politics 23(1), 21-51.

Serra, G. (2013). When Will Incumbents Avoid a Primary Challenge? Aggregation of Partial 
Information About Candidates' Valence. In Advances in Political Economy, pp. 217-247. Springer, Berlin, Heidelberg. DOI: 10.1007/978-3-642-35239-3_11.

Shugart, M. S. (2013). Between Science and Engineering: Reflections on the APSA Presidential Task Force on Political Science, Electoral Rules, and Democratic Governance: Why Ballot Structure Matters. Perspectives on Politics 11(3), 818-820.

Shugart, M. S., E. Moreno, and L. E. Fajardo (2005). Deepening Democracy by Renovating Political Practices: The Struggle for Electoral Reform in Colombia. Notre Dame University Press.

Shugart, M. S., M. E. Valdini, and K. Suominen (2005). Looking for Locals: Voter Information Demands and Personal Vote-Earning Attributes of Legislators under Proportional Representation. American Journal of Political Science 49(2), 437-449.

Snyder, James M., J. and M. M. Ting (2011). Electoral Selection with Parties and Primaries. American Journal of Political Science 55(4), 782-796.

Snyder, R. (2001). Scaling down: The subnational comparative method. Studies in comparative international development 36(1), 93-110. 


\title{
OnLine APPENDiX
}

\author{
Appendix A: INTERVIEWS
}

\section{A. Interviews}

From January to March 2016, we conducted a series of semi-structured interviews to learn how political candidates and party leaders think about list choice and its effects. In particular, we interviewed candidates for local councils regarding the municipal elections that took place in October 2015 in every municipality of Colombia.

The interviewees were selected from the country's five main regions: Andean, Caribbean, Pacific, Orinoquia, and Amazon. In each region we selected a representative municipality in terms of several covariates in which parties exclusively fielded open lists, and then matched it with a closed-list municipality within the same department with similar covariates. ${ }^{12}$

We selected parties that used both open and closed lists, and aimed to maintain a representative sample across the political spectrum. We selected the centrists Partido Alianza Verde, the leftist Polo Democrático Alternativo, and the center right Cambio Radical, and Partido de la U Party covering the political spectrum. Within each list we selected the candidate at the top of the list, the candidate in the middle of the list or the candidate at the bottom. In total, we sampled 102 candidates.

We obtained the candidates' phone numbers from the national party office. Of the 102 candidates, four had no phone number; of the 98 with a phone number (which is not necessarily their own private number, but may belong to a neighbor for example), 42 picked up the phone and 10 of them declined to be interviewed. We conducted a total of 32 interviews with the remaining candidates and achieved a balanced sample of 16 interviews in each list type. Seven interviews were conducted with candidates from the Cambio Radical, eight with the Partido

\footnotetext{
${ }^{12}$ We matched within the same department to minimize the physical distance between municipalities, to ensure closer cultural similarity and similar policies within the department. As stated in the introduction, Colombia is very diverse culturally across its regions, and making comparisons within departments ensured a better comparison.
} 
de la U, eleven with the Polo Democrático Alternativo, and six with Alianza Verde. Figure A1 displays a map of the geographical distribution of the interviewees across the country.

Figure A1: Map of council candidates interviewed. Colombia local elections 2015.

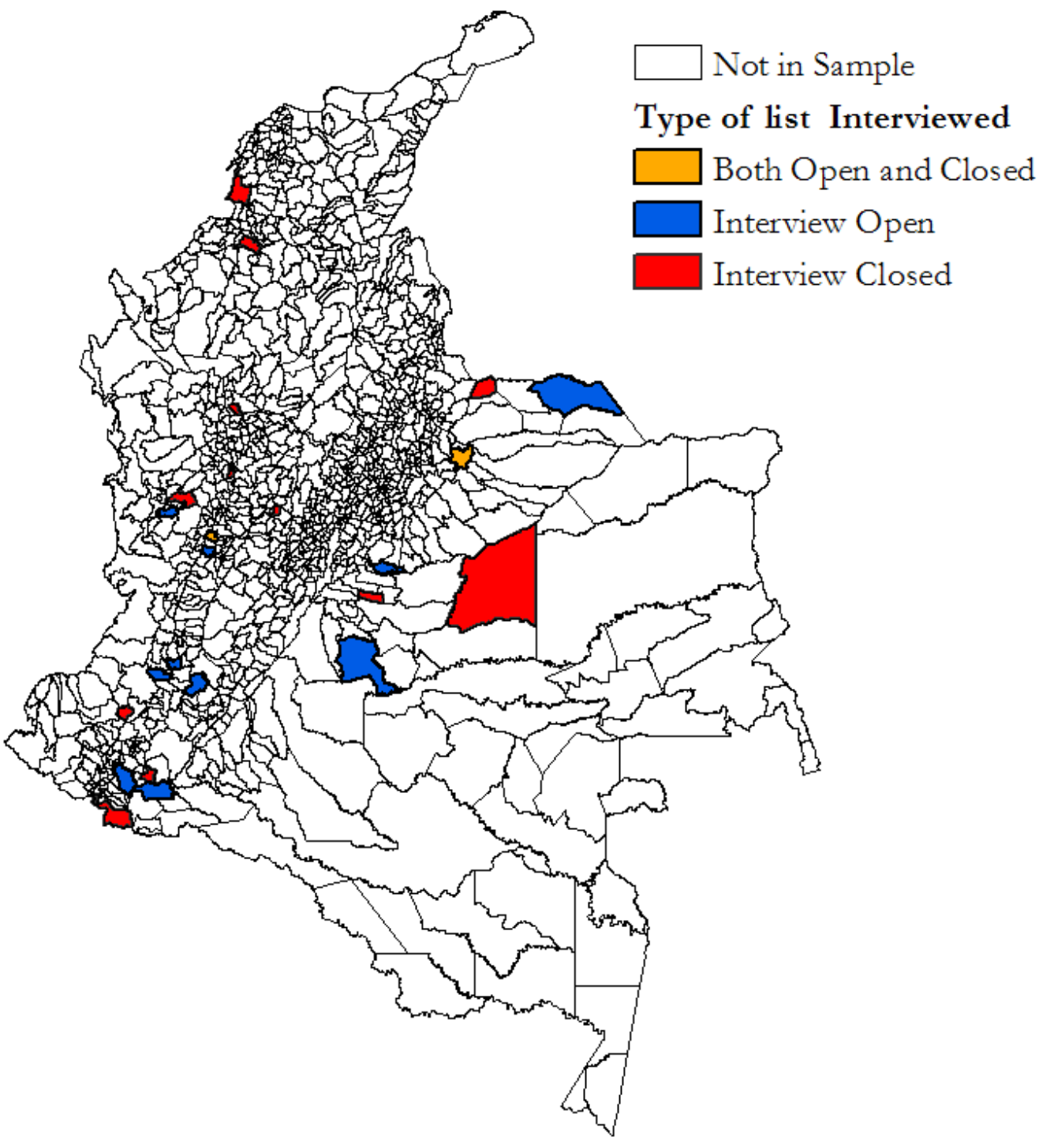

The interview questionnaire aims to capture information about who makes the decision about list types; which factors do the decision-makers take into account when choosing between open or closed lists; and what are, from their perspective, the potential advantages and 
disadvantages. 


\section{B. Questionnaire}

\section{A. General characteristics:}

A1. Who decided to go with an open or closed list in this election? Was this decision made at the national, department or local level? Is there a local party leader?

A2. How was that decision made? (Describe the process if there are more people involved than just the party leader).

A3. When was that decision made? (There is a deadline for submitting list choice, ask what happened around that deadline).

A4. Was the decision for/against closed/open list a contentious issue in the party?

A5. Generally speaking, who was in favor of closed list?

A6. Generally speaking, who was in favor of open list?

A7. Is it difficult to attract candidates in closed/open lists?

A8. Who decides the ranking? Are candidate characteristics taken into account for the ranking? Which ones?

-Was there any special consideration to place women on the list in different rankings?

A9. What do you think the voters think about the list choice? Do you think voters prefer open or closed lists? Why?

\section{B. General characteristics:}

B1. Do you have a clear idea what the other parties will do? (Before the electoral ballot is published).

B2. Is your list type decision influenced by what list type you think the other parties are going to adopt?

B3. Is the choice influenced by how competitive the race is with other parties?

\section{Advantages open list:}

C. In your personal opinion, what is the advantage of open list...

1. for the party?

2. for the politicians on the list?

3. for voters?

\section{Advantages closed list:}


D. In your personal opinion, what is the advantage of closed list...

1. for the party?

2. for the politicians on the list?

3. for voters?

\section{E. Open-ended question:}

Is there anything that you think is important for us to know about open and closed lists and how parties decide to favor one over the other?

\section{F. On party permission:}

How was the process of obtaining the party credentials to run (aval)? Did you obtain party permission aval from this party, or did you apply to others?

\section{Who decides on list type?}

According to our interviees, the decision to use open or closed lists is often made the candidates, or a subgroup of core candidates, running on the party's list. In some cases, all candidates gather before the deadline for submitting the list choice to the National Registry Office, and either vote on which ballot structure to use or discuss the issue until they reach a consensus. However, if there is a strong leader in the party, he/she will typically make the decision alone. Similarly, if the party runs for the mayor's office, the mayoral candidate will often decide on the list type, and, if a closed list is chosen, the ranking of the candidates on the list. In a few cases, the central office of the party instructs which list type the local party has to use. This, however, is rarely the case: with parties being highly decentralized and often serving as a mere

platform for a group of candidates to run on, it is probably not surprising that the decision over open or closed list is typically made by local candidates. 


\section{Appendix B: Descriptive statistics And ADDitional EVidence}

Table A1: Timeline for list type decisions

\begin{tabular}{ll}
\hline \hline Date & List type decision \\
\hline 25 July 2015 & Inscription of candidates in the local registry and selection of list type \\
28 July 2015 & Parties can start political campaign \\
31 July 2105 & Last day to announce changes in the lists. Changes are only possible if a candidate quits \\
2 August 2015 & Publication on the webpage of final list of candidates \\
25 October 2015 & Election date \\
1 January 2016 & Elected officials take office \\
\hline \hline
\end{tabular}

Table A2: Share of municipalities grouped by number of closed lists

\begin{tabular}{rrrrrrrr}
\hline \hline \multicolumn{8}{c}{ Number of Closed lists } \\
\hline Year & $\mathbf{0}$ & $\mathbf{1}$ & $\mathbf{2}$ & $\mathbf{3}$ & $\mathbf{4}$ & $\mathbf{5}$ & $\mathbf{6 +}$ \\
$\mathbf{2 0 0 3}$ & 59.8 & 22.0 & 9.8 & 4.4 & 2.2 & 1.1 & 0.6 \\
$\mathbf{2 0 0 7}$ & 80.5 & 16.4 & 2.6 & 0.4 & 0.2 & 0.0 & 0.0 \\
$\mathbf{2 0 1 1}$ & 72.9 & 23.6 & 2.9 & 0.5 & 0.1 & 0.0 & 0.0 \\
$\mathbf{2 0 1 5}$ & 54.7 & 32.6 & 10.4 & 1.8 & 0.4 & 0.2 & 0.0 \\
\hline \hline
\end{tabular}

Notes: The total number of municipalities for the different election years are 1087 (2003); 1098 (2007); 1099 (2011) and 1101 (2015).

Table A3: Share of municipalities grouped by share of closed lists

\begin{tabular}{rrrrrrrr}
\hline \hline - \% & of Closed lists (\# of Closed lists / Total Lists in Municipality): \\
\hline Year & $\mathbf{0 - 1 0 \%}$ & $\mathbf{1 0 - 2 0 \%}$ & $\mathbf{2 0 - 3 0 \%}$ & $\mathbf{3 0 - 4 0 \%}$ & $\mathbf{4 0 - 5 0 \%}$ & $\mathbf{5 0 - 6 0 \%}$ & $\mathbf{6 0 + \%}$ \\
$\mathbf{2 0 0 3}$ & 0.62 & 0.14 & 0.11 & 0.05 & 0.02 & 0.03 & 0.02 \\
$\mathbf{2 0 0 7}$ & 0.83 & 0.10 & 0.06 & 0.01 & 0.00 & 0.00 & 0.00 \\
$\mathbf{2 0 1 1}$ & 0.78 & 0.15 & 0.06 & 0.01 & 0.00 & 0.00 & 0.00 \\
$\mathbf{2 0 1 5}$ & 0.62 & 0.24 & 0.11 & 0.02 & 0.01 & 0.00 & 0.00 \\
\hline \hline
\end{tabular}

Notes: The total number of municipalities for the different election years are 1087 (2003); 1098 (2007); 1099 (2011) and 1101 (2015). 
Table A4: Conditional transition matrices for parties and candidates

\begin{tabular}{lcc} 
Parties & & \\
\hline \hline & Closed List t+1 & Open List t+1 \\
Closed List t & 0.26 & 0.74 \\
Open List t & 0.02 & 0.98 \\
\hline \hline
\end{tabular}

\section{Candidates}

\begin{tabular}{lcc}
\hline \hline & Closed List t+1 & Open List t+1 \\
Closed List t & 0.14 & 0.86 \\
Open List t & 0.16 & 0.84 \\
\hline
\end{tabular}

Note: Transition matrix shows the share of parties and candidates that run on open and closed lists in consecutive elections, and how they switch between list types. Estimates are conditional on parties running in consecutive elections $t$ and $t+1$.

\section{Table A5: Unonditional transition matrices for parties and candidates}

\begin{tabular}{cccc} 
Parties & \multicolumn{3}{c}{} \\
\hline \hline & Closed List t+1 & Open List t+1 & Exit t+1 \\
Closed List t & 0.088 & 0.256 & 0.656 \\
Open List t & 0.010 & 0.533 & 0.457 \\
\hline & & & \\
Candidates & & & \\
\hline \hline & Closed List t+1 & Open List t+1 & Not running t+1 \\
Closed List t & 0.03 & 0.183 & 0.787 \\
Open List t & 0.06 & 0.319 & 0.676 \\
\hline
\end{tabular}

Note: Transition matrix shows the share of parties and candidates that run on open and closed lists in consecutive elections, and how they switch between list types. Estimates are not conditional on parties running in consecutive elections $t$ and $t+1$. 
Table A6: Parties and list type choice across municipalities, 10 largest Colombian parties in local council elections 2003-2015

\begin{tabular}{|c|c|c|c|c|c|c|c|c|c|}
\hline & & \multicolumn{2}{|c|}{2003} & \multicolumn{2}{|c|}{2007} & \multicolumn{2}{|r|}{2011} & \multicolumn{2}{|c|}{2015} \\
\hline Name of party & Share of: & Munip & Closed list & Munip & Closed list & Munip & Closed list & Munip & Closed list \\
\hline LIBERAL COLOMBIANO & & 0.784 & 0.001 & 0.833 & 0.02 & 0.872 & 0.017 & 0.877 & 0.017 \\
\hline & \# of municip & 852 & 852 & 915 & 915 & 958 & 958 & 965 & 965 \\
\hline CONSERVADOR COLOMBIANO & & 0.647 & 0.023 & 0.770 & 0.002 & 0.869 & 0.001 & 0.878 & 0.000 \\
\hline & \# of municip & 703 & 703 & 845 & 845 & 955 & 955 & 967 & 967 \\
\hline CAMBIO RADICAL & & 0.216 & 0.174 & 0.674 & 0.007 & 0.887 & 0.007 & 0.913 & 0.022 \\
\hline & \# of municip & 235 & 235 & 740 & 740 & 975 & 975 & 1005 & 1005 \\
\hline SOCIAL DE UNIDAD NACIONAL & & & & 0.628 & 0.016 & 0.894 & 0.008 & 0.936 & 0.012 \\
\hline & \# of municip & 0 & 0 & 690 & 690 & 982 & 982 & 1030 & 1030 \\
\hline POLO DEMOCRATICO ALT. & & & & 0.567 & 0.069 & 0.444 & 0.113 & 0.433 & 0.115 \\
\hline & \# of municip & 0 & 0 & 623 & 623 & 488 & 488 & 477 & 477 \\
\hline ALIANZA SOCIAL INDIGENA. & & & & & & 0.536 & 0.037 & 0.607 & 0.040 \\
\hline & \# of municip & 0 & 0 & 0 & 0 & 589 & 589 & 668 & 668 \\
\hline PARTIDO VERDE & & & & 0.241 & 0.030 & 0.692 & 0.063 & & \\
\hline & \# of municip & 0 & 0 & 265 & 265 & 761 & 761 & 0 & 0 \\
\hline AUTO. INDIG.COL. & & 0.046 & 0.300 & 0.085 & 0.022 & 0.284 & 0.035 & 0.360 & 0.038 \\
\hline & \# of municip & 50 & 50 & 93 & 93 & 312 & 312 & 396 & 396 \\
\hline CENTRO DEMOCRATICO & & & & & & & & 0.738 & 0.429 \\
\hline & \# of municip & 0 & 0 & 0 & 0 & 0 & 0 & 813 & 813 \\
\hline UNION PATRIOTICA UP & & & & & & & & 0.729 & 0.030 \\
\hline & \# of municip & 0 & 0 & 0 & 0 & 0 & 0 & 803 & 803 \\
\hline Total number of municipalities in sample: & & & 1087 & & 1098 & & 1099 & & 1101 \\
\hline
\end{tabular}


Table A7: Number of parties switching between open and closed lists in consecutive elections

\begin{tabular}{|c|c|c|c|c|}
\hline Party Name/Election Period & $2007-2011$ & $2011-2015$ & $2015-2019$ & Total \\
\hline MOVIMIENTO MIRA & 37 & 57 & 79 & 173 \\
\hline POLO DEMOCRATICO ALTERNATIVO & 0 & 51 & 57 & 108 \\
\hline PARTIDO CAMBIO RADICAL COLOMBIANO & 31 & 15 & 23 & 69 \\
\hline PARTIDO LIBERAL COLOMBIANO & 11 & 23 & 20 & 54 \\
\hline PARTIDO SOCIAL DE UNIDAD NACIONAL PARTID & 0 & 12 & 15 & 27 \\
\hline PARTIDO NACIONAL CRISTIANO PNC & 0 & 0 & 24 & 24 \\
\hline MOVIMIENTO AUTORIDADES INDIGENAS DE COLOMBIA & 7 & 5 & 8 & 20 \\
\hline MOVIMIENTO ALIANZA SOC INDIGENA ASI & 20 & 0 & 0 & 20 \\
\hline PARTIDO CONSERVADOR COLOMBIANO & 14 & 5 & 0 & 19 \\
\hline MOVIMIENTO APERTURA LIBERAL & 17 & 0 & 0 & 17 \\
\hline MOVIMIENTO COLOMBIA VIVA & 12 & 0 & 0 & 12 \\
\hline MOVIMIENTO CONVERGENCIA CIUDADANA & 12 & 0 & 0 & 12 \\
\hline PARTIDO VERDE & 0 & 11 & 0 & 11 \\
\hline PARTIDO COLOMBIA DEMOCRATICA & 9 & 0 & 0 & 9 \\
\hline MOVIMIENTO COMPROMISO CIVICO CRISTIANO C & 1 & 0 & 0 & 1 \\
\hline MOVIMIENTO DE SALVACION NACIONAL & 1 & 0 & 0 & 1 \\
\hline Total Switchers & 172 & 179 & 226 & 577 \\
\hline
\end{tabular}

Table A8: Probability of winning a seat conditional on initial position in list

\begin{tabular}{cccc}
\hline Initial Position & Closed List & Open List & Combined \\
\hline 1 & 22.59 & 34.84 & 33.9 \\
2 & 9.46 & 21.94 & 21.02 \\
3 & 4.78 & 17.19 & 16.31 \\
4 & 3.49 & 14.43 & 13.73 \\
5 & 2.23 & 15 & 14.26 \\
6 & 1.71 & 12.85 & 12.29 \\
7 & 1.13 & 14.95 & 14.35 \\
8 & 1.04 & 11.94 & 11.49 \\
9 & 0.73 & 12.87 & 12.43 \\
10 & 0.52 & 13.77 & 13.33 \\
\hline
\end{tabular}




\section{Table A9: Descriptive statistics and differences in means across list type}

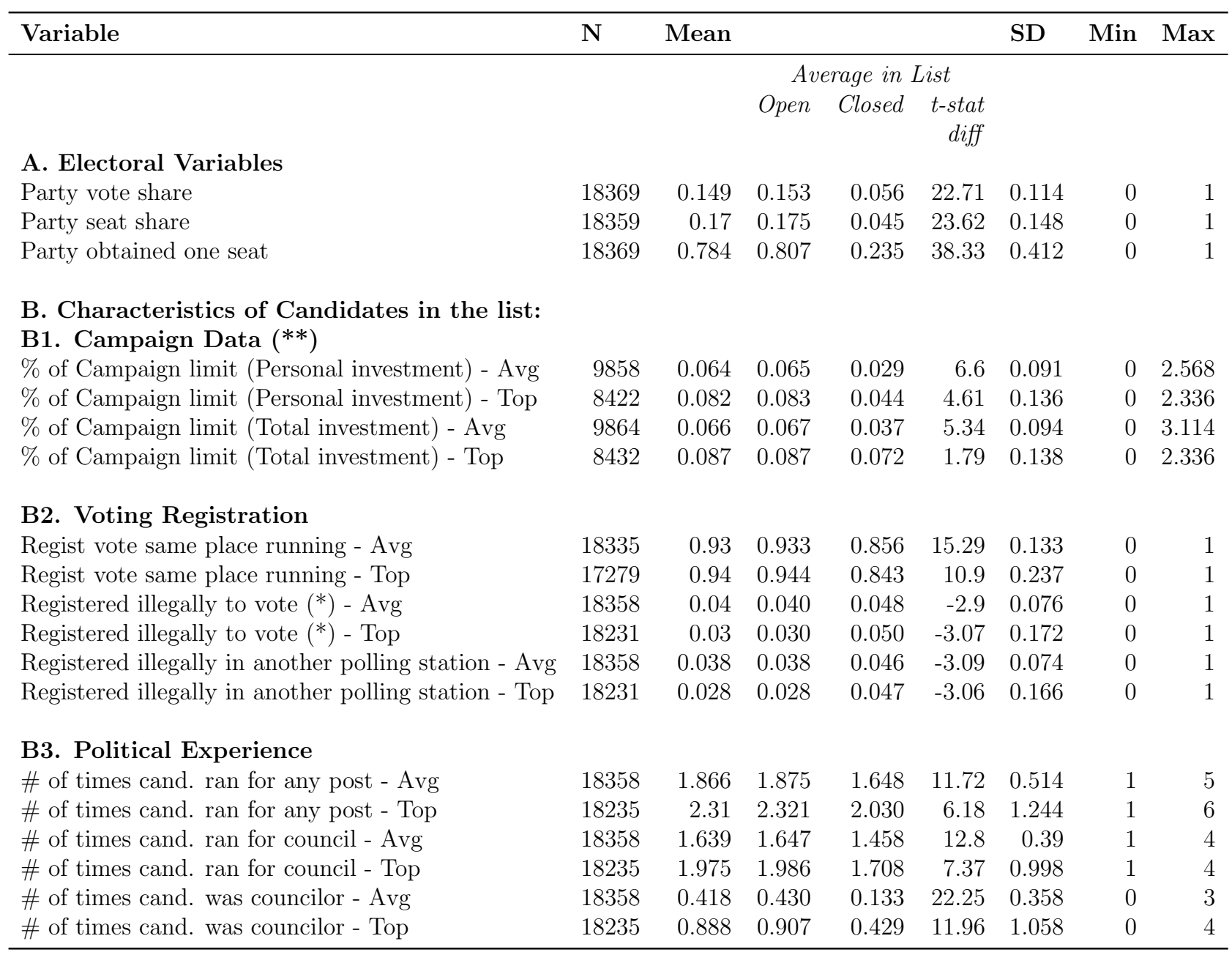

Notes: ${ }^{* *}$ denotes statistical significance at the $1 \%$ level, ${ }^{* *} 5 \%$ level, and $* 10 \%$ level. Number of total party lists: 18369. These are parties which are present in more than one election in the same municipality. Sample: Party lists in 1101 municipalities in Colombia council elections: 4 elections between 2003- 2015. (*) Use of a dead person fingerprint, having a duplicate ID, irregular inscription of ID, using a fake identity, Underage registration, Illegal migration of IDs implies a movement of ID to a new voting site in mass, typically in exchange of money. (**) Note that campaign data is only available for 2011 and 2015. 
Table A10: Predictors for party fielding closed lists

\begin{tabular}{|c|c|c|c|c|c|c|}
\hline & $(1)$ & $(2)$ & $(3)$ & $(4)$ & $(5)$ & $(6)$ \\
\hline Vote share for the party in $t-1$ & $\begin{array}{c}-0.158^{* * *} \\
(0.015)\end{array}$ & $\begin{array}{c}-0.0947^{* * *} * \\
(0.014)\end{array}$ & $\begin{array}{c}-0.0718^{* * *} \\
(0.014)\end{array}$ & $\begin{array}{c}-0.155^{* * *} \\
(0.016)\end{array}$ & $\begin{array}{c}-0.102^{* * *} \\
(0.015)\end{array}$ & $\begin{array}{c}-0.0751^{* * *} \\
(0.016)\end{array}$ \\
\hline Party chose closed list before & & $\begin{array}{c}0.171^{* * *} \\
(0.017)\end{array}$ & $\begin{array}{c}0.174^{* * *} \\
(0.017)\end{array}$ & & $\begin{array}{c}0.168^{* * *} \\
(0.019)\end{array}$ & $\begin{array}{c}0.170^{* * *} \\
(0.019)\end{array}$ \\
\hline \# of elections & & & $\begin{array}{c}-0.0122^{* * *} \\
(0.002)\end{array}$ & & & $\begin{array}{c}-0.013^{* * *} \\
(0.002)\end{array}$ \\
\hline Constant & $\begin{array}{c}0.055^{* * *} \\
(0.003)\end{array}$ & $\begin{array}{c}0.033^{* * *} \\
(0.003)\end{array}$ & $\begin{array}{c}0.068^{* * *} \\
(0.007)\end{array}$ & $\begin{array}{c}0.09 * * * \\
(0.034)\end{array}$ & $\begin{array}{c}0.06^{*} \\
(0.032)\end{array}$ & $\begin{array}{c}0.088^{* * *} \\
(0.033)\end{array}$ \\
\hline Municipality controls & & & & $\checkmark$ & $\checkmark$ & $\checkmark$ \\
\hline Observations & 11597 & 11597 & 11597 & 10755 & 10755 & 10755 \\
\hline R2 Adjusted & 0.014 & 0.074 & 0.077 & 0.013 & 0.067 & 0.071 \\
\hline
\end{tabular}

Notes: Table shows regression of a binary indicator of closed list on past electoral results, previously fielded list type, and number of elections that the party has run in the same municipality. Municipal control variables are: the number of elections that the party previously ran in this municipality, an indicator if the party also holds mayoral office, the number of council seats, the log distance to the capital, the log of the number of registered voters, and the number of years since municipality was created as an administrative unit. Standard errors are shown in parenthesis and are clustered at the municipality level. $* * *$ denotes statistical significance at the $1 \%$ level, ${ }^{* *} 5 \%$ level, and $* 10 \%$ level. The unit of analysis is a party in a municipality in an election.

\section{Detailed variable description}

\section{Table A11: Variables and sources.}

\begin{tabular}{|c|c|c|}
\hline Variable & Description & Source \\
\hline \multicolumn{3}{|c|}{ Panel A. Electoral: Party-level covariates } \\
\hline Closed list & Dummy $=1$ if party choses closed list & $\begin{array}{l}\text { Electoral data from the } \\
\text { National Registry }\end{array}$ \\
\hline Party vote share & Total party votes / Total votes in election & $\begin{array}{l}\text { Electoral data from the } \\
\text { National Registry }\end{array}$ \\
\hline Party seat share & Total seats obtained by party / Total seats available & $\begin{array}{l}\text { Electoral data from the } \\
\text { National Registry }\end{array}$ \\
\hline Party obtained one seat & Dummy $=1$, if the party got at least one seat & $\begin{array}{l}\text { Electoral data from the } \\
\text { National Registry }\end{array}$ \\
\hline$\%$ of party list filled & $\begin{array}{l}\text { Total number of candidates in list (\% List fill) / Maximum number of seats } \\
\text { available in the municipality }\end{array}$ & $\begin{array}{l}\text { Electoral data from the } \\
\text { National Registry }\end{array}$ \\
\hline $\begin{array}{l}\text { Party is the incumbent } \\
\text { party }\end{array}$ & Dummy $=1$, if the party holds the Mayor's office when elections are held & Own coding \\
\hline $\begin{array}{l}\% \text { of previous incum- } \\
\text { bents in list }\end{array}$ & $\begin{array}{l}\text { Total number of candidates who has held council office at least once / Total } \\
\text { number of candidates in list }\end{array}$ & $\begin{array}{l}\text { Electoral data from the } \\
\text { National Registry }\end{array}$ \\
\hline Party experience in years & Number of years the party has participated in the municipality & Own coding \\
\hline
\end{tabular}

Panel B. Electoral: Municipality-level covariates 
Table A11 - Variables and sources, continued from previous page

\begin{tabular}{|c|c|c|}
\hline \multicolumn{3}{|c|}{ Table A11 - Variables and sources, continued from previous page } \\
\hline Variable & Description & Source \\
\hline Invalid vote $\%$ & Total invalid votes (Null votes + Unmarked votes) / Total votes in election & $\begin{array}{l}\text { Electoral data from the } \\
\text { National Registry }\end{array}$ \\
\hline Unmarked vote \% & Total unmarked votes / Total votes in election & $\begin{array}{l}\text { Electoral data from the } \\
\text { National Registry }\end{array}$ \\
\hline Null votes percent & Total null votes / Total votes in election & $\begin{array}{l}\text { Electoral data from the } \\
\text { National Registry }\end{array}$ \\
\hline Voter turnout & Total votes cast / Number of registered voters & $\begin{array}{l}\text { Electoral data from the } \\
\text { National Registry }\end{array}$ \\
\hline Total seats available & Number of sets available for local councils & $\begin{array}{l}\text { Electoral data from the } \\
\text { National Registry }\end{array}$ \\
\hline
\end{tabular}

\section{Panel C. Additional municipality covariates}

Distance to department Straight line distance in $\mathrm{km}$, to the capital of the department where the capital, km
Straight line distance in $\mathrm{km}$, to the capital of the department where the
municipality is located
\# of registered voters

Years since foundation
Number of registered voters in the municipality

Years since the foundation of the municipality
Estimates by CEDE Universidad de los Andes, based on Agustin Codazzi Geographic Institute (Colombia's National Geographic Institute)

National Registry Office CEDE municipality panel

\section{Panel D. Individual-level covariates}

\section{Campaign data}

Personal campaign effort - Total value

Personal campaign effort

Total campaign effort Total value

Total campaign effort $\%$ of limit - \% of limit

Individual effort that accounts for the campaign spending that is directly related to the individual using its own funds or raising own funds. Value in Colombian pesos.

Personal campaign effort / Total campaign income allowed by law.

Campaign effort from all sources. Includes contributions i) from personal income, spouses or family, ii) Private donors, iii) Credit from banks. Value in Colombian pesos.

Campaign effort / Total campaign income allowed by law

Candidate political background

\# of times cand. ran for any post

\# of times candidate in list ran for any elected post (excluding current election)

\# of times cand. ran for council

\# of times cand. was councilor

Illegal registration of ID
\# of times candidate in list ran for any local council (excluding current election)

\# of times candidate was councilor

Dummy $=1$, if the candidate has registered illegally to vote, e.g., by using a dead person's ID, a duplicate ID, a fake identity, registered while under 18, and was paid to vote at a new polling station.
National Electoral Commission

National Electoral Commission

National Electoral Commission

National electoral commission.

Own coding

Own coding

Own coding

National Registry of Colombia

Continued on next page 


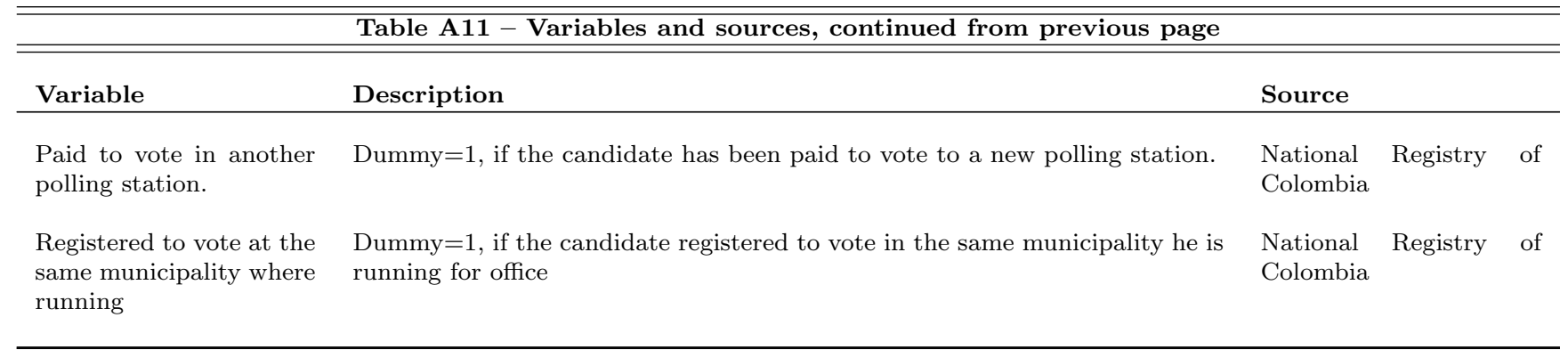

E. Robustness analyses controlling for previous party experience

\section{Table A12: Effect of open lists on electoral outcomes. Controlling for party experience}

\begin{tabular}{lccc}
\hline \hline & $(1)$ & $(2)$ & $(3)$ \\
& Party vote share & Party seat share & Party one seat \\
\hline & & & \\
Open list & $\left(0.049^{* * *}\right.$ & $0.055^{* * *}$ & $0.198^{* * *}$ \\
& & $(0.005)$ & $(0.021)$ \\
Party experience in municip. & $\checkmark$ & & \\
Year dummies & $\checkmark$ & $\checkmark$ & $\checkmark$ \\
Mun FE x Party FE & $\checkmark$ & $\checkmark$ & $\checkmark$ \\
& & $\checkmark$ & $\checkmark$ \\
Mean dep. var & 0.077 & 0.073 & 0.392 \\
Effect size $(\Delta \%)$ & 63.4 & 74.9 & 50.5 \\
$95 \%$ CI LB & 53.2 & 60.2 & 40.3 \\
95\% CI UB & 73.6 & 89.5 & 60.8 \\
Municipalities & 1101 & 1101 & 1101 \\
Observations & 18369 & 18357 & 18382 \\
\hline \hline
\end{tabular}

Notes: Standard errors are shown in parenthesis and are clustered at the municipality level. *** denotes statistical significance at the $1 \%$ level, $* * 5 \%$ level, and $* 10 \%$ level. The unit of analysis is a party in a municipality in an election. 
Table A13: Effect of open list on campaign investment, controlling for party experience

\begin{tabular}{|c|c|c|c|c|c|c|c|c|}
\hline & $(1)$ & $(2)$ & $(3)$ & $(4)$ & $(5)$ & $(6)$ & $(7)$ & $(8)$ \\
\hline & \multicolumn{4}{|c|}{$\%$ of Campaign limit (Personal investment) } & \multicolumn{4}{|c|}{$\%$ of Campaign limit (Total investment) } \\
\hline & Average & Top & Marginal & Bottom & Average & Top & Marginal & Bottom \\
\hline Open list & $\begin{array}{c}0.017^{* * *} \\
(0.004)\end{array}$ & $\begin{array}{c}0.008 \\
(0.008)\end{array}$ & $\begin{array}{c}0.022^{* * *} \\
(0.005)\end{array}$ & $\begin{array}{c}0.019^{* * *} \\
(0.006)\end{array}$ & $\begin{array}{c}0.017^{* * *} \\
(0.005)\end{array}$ & $\begin{array}{c}-0.000 \\
(0.010)\end{array}$ & $\begin{array}{c}0.022^{* * *} \\
(0.006)\end{array}$ & $\begin{array}{c}0.024^{* * *} * \\
(0.006)\end{array}$ \\
\hline Party experience in municip. & $\checkmark$ & $\checkmark$ & $\checkmark$ & $\checkmark$ & $\checkmark$ & $\checkmark$ & $\checkmark$ & $\checkmark$ \\
\hline Year dummies & $\checkmark$ & $\checkmark$ & $\checkmark$ & $\checkmark$ & $\checkmark$ & $\checkmark$ & $\checkmark$ & $\checkmark$ \\
\hline Mun FE x Party FE & $\checkmark$ & $\checkmark$ & $\checkmark$ & $\checkmark$ & $\checkmark$ & $\checkmark$ & $\checkmark$ & $\checkmark$ \\
\hline Mean dep. var & 0.028 & 0.039 & 0.029 & 0.027 & 0.039 & 0.080 & 0.040 & 0.034 \\
\hline Effect size $(\Delta \%)$ & 59.0 & 21.0 & 77.0 & 68.5 & 43.6 & -0.1 & 55.4 & 71.2 \\
\hline $95 \%$ CI LB & 31.4 & -20.4 & 43.9 & 28.7 & 20.9 & -25.8 & 28.5 & 37.1 \\
\hline $95 \%$ CI UB & 86.6 & 62.3 & 110.1 & 108.4 & 66.3 & 25.6 & 82.4 & 105.3 \\
\hline Municipalities & 1072 & 1022 & 1043 & 1058 & 1072 & 1022 & 1044 & 1058 \\
\hline Observations & 8668 & 6487 & 7149 & 7942 & 8674 & 6497 & 7159 & 7958 \\
\hline
\end{tabular}

Notes: Standard errors are shown in parenthesis and are clustered at the municipality level. *** denotes statistical significance at the $1 \%$ level, $* * 5 \%$ level, and * $10 \%$ level. The unit of analysis is a party in a municipality in an election. "Top" are candidates located at the top of the list, "marginal" candidates are located in the second and third position, and "bottom" are candidates listed fourth to last (measured before the election). 


\section{Table A14: Effect of open list on political experience, controlling for party experience}

\begin{tabular}{|c|c|c|c|c|c|c|c|c|}
\hline & (1) & (2) & (3) & (4) & (5) & (6) & (7) & (8) \\
\hline & \multicolumn{4}{|c|}{ \# of times cand. ran any post } & \multicolumn{4}{|c|}{ \# of times cand. ran council } \\
\hline & Average & Top & Marginal & Bottom & Average & Top & Marginal & Bottom \\
\hline Open list & $\begin{array}{c}0.081^{* * *} \\
(0.026)\end{array}$ & $\begin{array}{c}0.012 \\
(0.052)\end{array}$ & $\begin{array}{c}0.055 \\
(0.040)\end{array}$ & $\begin{array}{c}0.244^{* * *} \\
(0.028)\end{array}$ & $\begin{array}{l}0.037^{*} \\
(0.019)\end{array}$ & $\begin{array}{c}0.004 \\
(0.043)\end{array}$ & $\begin{array}{c}0.030 \\
(0.033)\end{array}$ & $\begin{array}{c}0.143^{* * *} \\
(0.023)\end{array}$ \\
\hline Party experience in munip. & $\checkmark$ & $\checkmark$ & $\checkmark$ & $\checkmark$ & $\checkmark$ & $\checkmark$ & $\checkmark$ & $\checkmark$ \\
\hline Year dummies & $\checkmark$ & $\checkmark$ & $\checkmark$ & $\checkmark$ & $\checkmark$ & $\checkmark$ & $\checkmark$ & $\checkmark$ \\
\hline Mun FE x Party FE & $\checkmark$ & $\checkmark$ & $\checkmark$ & $\checkmark$ & $\checkmark$ & $\checkmark$ & $\checkmark$ & $\checkmark$ \\
\hline Mean dep. var & 1.715 & 2.130 & 1.777 & 1.569 & 1.521 & 1.814 & 1.573 & 1.408 \\
\hline Effect size $(\Delta \%)$ & 4.7 & 0.5 & 3.1 & 15.5 & 2.4 & 0.2 & 1.9 & 10.1 \\
\hline $95 \%$ CI LB & 1.7 & -4.3 & -1.4 & 12.0 & -0.0 & -4.5 & -2.1 & 6.9 \\
\hline 95\% CI UB & 7.7 & 5.4 & 7.5 & 19.0 & 4.9 & 4.9 & 6.0 & 13.3 \\
\hline Municipalities & 1101 & 1101 & 1101 & 1101 & 1101 & 1101 & 1101 & 1101 \\
\hline \multirow{4}{*}{ Observations } & 18365 & 18206 & 18091 & 17165 & 18365 & 18206 & 18091 & 17165 \\
\hline & $(11)$ & $(12)$ & $(13)$ & $(14)$ & & & & \\
\hline & \# of til & les cand. & $\mathrm{n}$ list was $\mathrm{c}$ & ouncilor & & & & \\
\hline & Average & Top & Marginal & Bottom & & & & \\
\hline Open list & $\begin{array}{c}0.058^{* * *} \\
(0.012)\end{array}$ & $\begin{array}{c}-0.081^{* *} \\
(0.036)\end{array}$ & $\begin{array}{c}0.034 \\
(0.022)\end{array}$ & $\begin{array}{c}0.129^{* * *} \\
(0.014)\end{array}$ & & & & \\
\hline Party experience in munip. & $\checkmark$ & $\checkmark$ & $\checkmark$ & $\checkmark$ & & & & \\
\hline Year dummies & $\checkmark$ & $\checkmark$ & $\checkmark$ & $\checkmark$ & & & & \\
\hline Mun FE x Party FE & $\checkmark$ & $\checkmark$ & $\checkmark$ & $\checkmark$ & & & & \\
\hline Mean dep. var & 0.194 & 0.507 & 0.235 & 0.135 & & & & \\
\hline Effect size $(\Delta \%)$ & 30.0 & -16.0 & 14.3 & 95.3 & & & & \\
\hline $95 \%$ CI LB & 18.3 & -30.0 & -4.4 & 75.6 & & & & \\
\hline 95\% CI UB & 41.8 & -2.1 & 33.0 & 115.0 & & & & \\
\hline Municipalities & 1101 & 1101 & 1101 & 1101 & & & & \\
\hline Observations & 18365 & 18206 & 18091 & 17165 & & & & \\
\hline
\end{tabular}

Notes: Standard errors are shown in parenthesis and are clustered at the municipality level. *** denotes statistical significance at the $1 \%$ level, ${ }^{* *} 5 \%$ level, and * $10 \%$ level. The unit of analysis is a party in a municipality in an election. "Top" are candidates located at the top of the list, "marginal" candidates are located in the second and third position, and "bottom" are candidates listed fourth to last (measured before the election). 


\section{Table A15: Effect of list type on engagement in constituency, controlling for party experience}

\begin{tabular}{lcccc}
\hline \hline & $(1)$ & $(2)$ & $(3)$ & $(4)$ \\
& Average & Top & Marginal & Bottom \\
\hline Open list & & & & \\
& $0.041^{* * *}$ & $0.071^{* * *}$ & $0.036^{* * *}$ & $0.036^{* * *}$ \\
& $(0.009)$ & $(0.018)$ & $(0.014)$ & $(0.012)$ \\
Party experience in municip & $\checkmark$ & $\checkmark$ & $\checkmark$ & $\checkmark$ \\
Year dummies & $\checkmark$ & $\checkmark$ & $\checkmark$ & $\checkmark$ \\
Mun FE x Party FE & $\checkmark$ & $\checkmark$ & $\checkmark$ & $\checkmark$ \\
& & & & \\
Mean dep. var & 0.897 & 0.889 & 0.905 & 0.902 \\
Effect size $(\Delta \%)$ & 4.6 & 8.0 & 4 & 4 \\
95\% CI LB & 2.6 & 4 & 1.0 & 1.3 \\
95\% CI UB & 6.6 & 11.9 & 6.9 & 6.7 \\
Municipalities & 1101 & 1101 & 1101 & 1101 \\
Observations & 18333 & 16944 & 17910 & 17094 \\
\hline \hline
\end{tabular}

Notes: Standard errors are shown in parenthesis and are clustered at the municipality level. ${ }^{* * *}$ denotes statistical significance at the $1 \%$ level, ** $5 \%$ level, and * $10 \%$ level. The unit of analysis is a party in a municipality in an election. "Top" are candidates located at the top of the list, "marginal" candidates are located in the second and third position, and "bottom" are candidates listed fourth to last (measured before the election).

Table A16: Effect of open list on election fraud, coontrolling for party experience

\begin{tabular}{|c|c|c|c|c|c|c|c|c|}
\hline & (1) & (2) & $(3)$ & (4) & $(5)$ & (6) & (7) & $(8)$ \\
\hline & \multicolumn{4}{|c|}{ Registered Ilegally to vote } & \multicolumn{4}{|c|}{ Voted illegally in different polling station } \\
\hline & Average & Top & Marginal & Bottom & Average & Top & Marginal & Bottom \\
\hline Open list & $\begin{array}{c}-0.013^{* *} \\
(0.005)\end{array}$ & $\begin{array}{c}-0.017 \\
(0.012)\end{array}$ & $\begin{array}{c}-0.021^{* *} \\
(0.009)\end{array}$ & $\begin{array}{c}-0.018^{* *} \\
(0.008)\end{array}$ & $\begin{array}{c}-0.014^{* * *} \\
(0.005)\end{array}$ & $\begin{array}{c}-0.021^{*} \\
(0.011)\end{array}$ & $\begin{array}{c}-0.022^{* * *} \\
(0.009)\end{array}$ & $\begin{array}{c}-0.017^{* *} \\
(0.008)\end{array}$ \\
\hline Party experience in municipality & $\checkmark$ & $\checkmark$ & $\checkmark$ & $\checkmark$ & $\checkmark$ & $\checkmark$ & $\checkmark$ & $\checkmark$ \\
\hline Year dummies & $\checkmark$ & $\checkmark$ & $\checkmark$ & $\checkmark$ & $\checkmark$ & $\checkmark$ & $\checkmark$ & $\checkmark$ \\
\hline Mun FE x Party FE & $\checkmark$ & $\checkmark$ & $\checkmark$ & $\checkmark$ & $\checkmark$ & $\checkmark$ & $\checkmark$ & $\checkmark$ \\
\hline Mean Dep. Var & 0.045 & 0.048 & 0.041 & 0.046 & 0.043 & 0.042 & 0.039 & 0.044 \\
\hline Effect Size $(\Delta \%)$ & -27.9 & -35.3 & -50.2 & -38.7 & -33.5 & -51 & -56.6 & -38.45 \\
\hline $95 \%$ CI LB & -49.2 & -82.7 & -92.3 & -72.7 & -55.7 & -102.6 & -99.8 & -73.6 \\
\hline 95\% CI UB & -6.5 & 12.1 & -8.9 & -4.7 & -11.4 & 0.7 & -13.4 & -3.3 \\
\hline Municipalities & 1101 & 1101 & 1101 & 1101 & 1101 & 1101 & 1101 & 1101 \\
\hline Observations & 18365 & 18201 & 18091 & 17165 & 18365 & 18201 & 18091 & 17165 \\
\hline
\end{tabular}

Notes: Standard errors are shown in parenthesis and are clustered at the municipality level. *** denotes statistical significance at the $1 \%$ level, ${ }^{* *} 5 \%$ level, and * $10 \%$ level. The unit of analysis is a party in a municipality in an election. "Top" are candidates located at the top of the list, "marginal" candidates are located in the second and third position, and "bottom" are candidates listed fourth to last (measured before the election). 
F. Robustness analyses, iteratively excluding major parties

Table A17: Effect of open lists on electoral outcomes, iteratively excluding the major parties

\begin{tabular}{|c|c|c|c|}
\hline & $\begin{array}{c}(1) \\
\text { Party vote share }\end{array}$ & $\begin{array}{c}(2) \\
\text { Party seat share }\end{array}$ & $\begin{array}{c}(3) \\
\text { Party one seat }\end{array}$ \\
\hline $\begin{array}{l}\text { Open List } \\
\text { (PARTIDO LIBERAL) }\end{array}$ & $\begin{array}{c}0.041^{* * *} \\
(0.004)\end{array}$ & $\begin{array}{c}0.045^{* * *} \\
(0.005)\end{array}$ & $\begin{array}{c}0.184^{* * *} \\
(0.021)\end{array}$ \\
\hline $\begin{array}{l}\text { Open List } \\
\text { (PARTIDO CONSERVADOR) }\end{array}$ & $\begin{array}{c}0.048^{* * *} \\
(0.004)\end{array}$ & $\begin{array}{c}0.054^{* * *} \\
(0.006)\end{array}$ & $\begin{array}{l}0.201^{* * *} \\
(0.021)\end{array}$ \\
\hline $\begin{array}{l}\text { Open List } \\
\text { (PARTIDO CAMBIO RADICAL) }\end{array}$ & $\begin{array}{c}0.043^{* * *} \\
(0.004)\end{array}$ & $\begin{array}{l}0.046^{* * *} \\
(0.006)\end{array}$ & $\begin{array}{l}0.170^{* * *} \\
(0.021)\end{array}$ \\
\hline $\begin{array}{l}\text { Open List } \\
\text { (PARTIDO DE LA U) }\end{array}$ & $\begin{array}{c}0.048^{* * *} \\
(0.004)\end{array}$ & $\begin{array}{c}0.053^{* * *} \\
(0.005)\end{array}$ & $\begin{array}{c}0.198^{* * *} \\
(0.021)\end{array}$ \\
\hline $\begin{array}{l}\text { Open List } \\
\text { (POLO DEMOCRATICO ALTERNATIVO) }\end{array}$ & $\begin{array}{c}0.056^{* * *} \\
(0.004)\end{array}$ & $\begin{array}{c}0.067^{* * *} \\
(0.006)\end{array}$ & $\begin{array}{l}0.212^{* * *} \\
(0.024)\end{array}$ \\
\hline $\begin{array}{l}\text { Open List } \\
\text { (MOVIMIENTO ALIANZA SOC INDIGENA) }\end{array}$ & $\begin{array}{c}0.051^{* * *} \\
(0.004)\end{array}$ & $\begin{array}{c}0.056^{* * *} \\
(0.005)\end{array}$ & $\begin{array}{c}0.199^{* * *} \\
(0.021)\end{array}$ \\
\hline $\begin{array}{l}\text { Open List } \\
\text { (PARTIDO VERDE) }\end{array}$ & $\begin{array}{c}0.049^{* * *} \\
(0.004)\end{array}$ & $\begin{array}{c}0.056^{* * *} \\
(0.006)\end{array}$ & $\begin{array}{c}0.198^{* * *} \\
(0.021)\end{array}$ \\
\hline $\begin{array}{l}\text { Open List } \\
\text { (AUTORIDADES INDIGENAS DE COLOMBIA) }\end{array}$ & $\begin{array}{c}0.048^{* * *} \\
(0.004)\end{array}$ & $\begin{array}{l}0.054^{* * *} \\
(0.006)\end{array}$ & $\begin{array}{l}0.182^{* * *} \\
(0.021)\end{array}$ \\
\hline
\end{tabular}

Notes: Notes: Standard errors are shown in parenthesis and are clustered at the municipality level. *** denotes statistical significance at the $1 \%$ level, ${ }^{* *} 5 \%$ level, and $* 10 \%$ level. Omitted party in parentheses. 
G. Robustness analyses, controlling for muncipality-specific linear time trends

\section{Table A18: Effect of open lists on electoral outcomes, controlling for party specific trend}

\begin{tabular}{lccc}
\hline \hline & $(1)$ & $(2)$ & $(3)$ \\
& Party vote share & Party seat share & Party one seat \\
\hline & $0.080^{* * *}$ & $0.096^{* * *}$ & $0.314^{* * *}$ \\
Open list & $(0.006)$ & $(0.008)$ & $(0.025)$ \\
& & & \\
Year dummies & $\checkmark$ & $\checkmark$ & $\checkmark$ \\
Party FE x Mun FE x Time trend & $\checkmark$ & $\checkmark$ & $\checkmark$ \\
& & & \\
Mean dep. var & 0.077 & 0.073 & 0.392 \\
Effect size $(\Delta \%)$ & 104.63 & 131.58 & 60.1 \\
95\% CI LB & 88.8 & 111.4 & 92.3 \\
95\% CI UB & 120.5 & 151.8 & 1101 \\
Municipalities & 1101 & 1101 & 18382 \\
Observations & 18369 & 18357 & \\
\hline
\end{tabular}

Notes: Notes: Standard errors are shown in parenthesis and are clustered at the municipality level. *** denotes statistical significance at the $1 \%$ level, ${ }^{* *} 5 \%$ level, and ${ }^{*} 10 \%$ level. The unit of analysis is a party in a municipality in an election.

\section{Table A19: Effect of open list on candidate characteristics, controlling for party specific time trends}

\begin{tabular}{|c|c|c|c|c|c|c|c|c|}
\hline & $\begin{array}{c}(1) \\
\text { Pers Camp. Invest }\end{array}$ & $\begin{array}{c}(2) \\
\text { Total Camp Invest }\end{array}$ & $\begin{array}{c}(3) \\
\text { Reg. Vote }\end{array}$ & $\begin{array}{c}(4) \\
\text { Illegal Vote }\end{array}$ & $\begin{array}{c}(5) \\
\text { Illegal Vote Diff. }\end{array}$ & $\begin{array}{c}(6) \\
\text { Ran Pub. Office } \\
\end{array}$ & $\begin{array}{c}(7) \\
\text { Ran Council } \\
\end{array}$ & $\begin{array}{c}(8) \\
\text { Councilor } \\
\end{array}$ \\
\hline Open list & $\begin{array}{c}0.025^{* * *} \\
(0.006)\end{array}$ & $\begin{array}{c}0.024^{* * *} \\
(0.007)\end{array}$ & $\begin{array}{c}0.058^{* * *} \\
(0.013)\end{array}$ & $\begin{array}{c}-0.011^{* *} \\
(0.005)\end{array}$ & $\begin{array}{c}-0.012^{* *} \\
(0.005)\end{array}$ & $\begin{array}{c}0.183^{* * *} \\
(0.032)\end{array}$ & $\begin{array}{c}0.100^{* * *} * \\
(0.023)\end{array}$ & $\begin{array}{c}0.160 * * * \\
(0.015)\end{array}$ \\
\hline Year dummies & $\checkmark$ & $\checkmark$ & $\checkmark$ & $\checkmark$ & $\checkmark$ & $\checkmark$ & $\checkmark$ & $\checkmark$ \\
\hline Party FE x Mun FE x Trend & $\checkmark$ & $\checkmark$ & $\checkmark$ & $\checkmark$ & $\checkmark$ & $\checkmark$ & $\checkmark$ & $\checkmark$ \\
\hline Mean dep. var & 0.028 & 0.039 & 0.897 & 0.045 & 0.043 & 1.715 & 1.521 & 0.194 \\
\hline Effect size $(\Delta \%)$ & 88.1 & 61.8 & 6.5 & -23.6 & -28.6 & 10.7 & 6.6 & 82.3 \\
\hline $95 \%$ CI LB & 47.3 & 28.4 & 3.6 & -46.1 & -52.0 & 7.0 & 3.7 & 67.4 \\
\hline $95 \%$ CI UB & 128.9 & 95.1 & 9.4 & -1.1 & -5.1 & 14.3 & 9.5 & 97.2 \\
\hline Municipalities & 1072 & 1072 & 1101 & 1101 & 1101 & 1101 & 1101 & 1101 \\
\hline Observations & 8668 & 8674 & 18333 & 18365 & 18365 & 18365 & 18365 & 18365 \\
\hline
\end{tabular}

Notes: Standard errors are shown in parenthesis and are clustered at the municipality level. *** denotes statistical significance at the $1 \%$ level, ${ }^{* *} 5 \%$ level, and * $10 \%$ level. The unit of analysis is a party in a municipality in an election. "Top" are candidates located at the top of the list, "marginal" candidates are located in the second and third position, and "bottom" are candidates listed fourth to last (measured before the election).Pers Camp. Invest. (\% of Campaign limit (Personal investment)), Total Camp. Invest. (\% of Campaign limit (Total investment)), Reg. Vote (Registered to vote in the same place running), Illegal Vote (Registered Illegally to vote), Illegal Vote Diff. (Voted illegally in different polling station), Ran Pub. Office (\# of times cand. ran for any elected post), Ran council (\# of times cand. in list ran for local council), and Councilor (\# of times cand. in list was elected council). 
H. Robustness analyses, controlling for past vote share

\section{Table A20: Effect of Open lists on electoral outcomes, controlling for past vote share}

\begin{tabular}{lccc}
\hline \hline & $(1)$ & $(2)$ & $(3)$ \\
& Party vote share & Party seat share & Party one seat \\
\hline & $0.041^{* * *}$ & $0.047^{* * *}$ & $0.191^{* * *}$ \\
Open list & $(0.004)$ & $(0.005)$ & $(0.020)$ \\
& & & \\
Party vote share t-1 & $\checkmark$ & $\checkmark$ & $\checkmark$ \\
Year dummies & $\checkmark$ & $\checkmark$ & $\checkmark$ \\
Mun FE x Party FE & $\checkmark$ & $\checkmark$ & $\checkmark$ \\
& & & \\
Mean dep. var & 0.077 & 0.073 & 0.392 \\
Effect size $(\Delta \%)$ & 54.2 & 64.4 & 48.6 \\
$95 \%$ CI LB & 44.3 & 49.8 & 38.4 \\
$95 \%$ CI UB & 64 & 1101 & 58.8 \\
Municipalities & 1101 & 18357 & 1101 \\
Observations & 18369 & & 18382 \\
\hline \hline
\end{tabular}

Notes: Notes: Standard errors are shown in parenthesis and are clustered at the municipality level. *** denotes statistical significance at the $1 \%$ level, ${ }^{* *} 5 \%$ level, and ${ }^{*} 10 \%$ level. The unit of analysis is a party in a municipality in an election.

Table A21: Effect of open list on candidate characteristics, controlling for past vote share

\begin{tabular}{|c|c|c|c|c|c|c|c|c|}
\hline & $\begin{array}{c}(1) \\
\text { Pers Camp. Invest }\end{array}$ & $\begin{array}{c}(2) \\
\text { Total Camp Invest }\end{array}$ & $\begin{array}{c}\text { (3) } \\
\text { Reg. Vote }\end{array}$ & $\begin{array}{c}(4) \\
\text { Illegal Vote }\end{array}$ & $\begin{array}{c}\text { Illegal Vote Diff. } \\
\text { Il }\end{array}$ & $\begin{array}{c}(6) \\
\text { Ran Pub. Office }\end{array}$ & $\begin{array}{c}(7) \\
\text { Ran council }\end{array}$ & $\begin{array}{c}(8) \\
\text { Councilor }\end{array}$ \\
\hline Open list & $\begin{array}{c}0.015 * * * \\
(0.004)\end{array}$ & $\begin{array}{c}0.015 * * * \\
(0.004)\end{array}$ & $\begin{array}{c}0.041 * * * \\
(0.009)\end{array}$ & $\begin{array}{c}-0.012^{* *} \\
(0.005)\end{array}$ & $\begin{array}{c}-0.014^{* * * *} \\
(0.005)\end{array}$ & $\begin{array}{c}0.084^{* * *} \\
(0.026)\end{array}$ & $\begin{array}{l}0.042^{* *} \\
(0.019)\end{array}$ & $\begin{array}{c}0.060^{* * *} \\
(0.012)\end{array}$ \\
\hline Party vote share $\mathrm{t}-1$ & $\checkmark$ & $\checkmark$ & $\checkmark$ & $\checkmark$ & $\checkmark$ & $\checkmark$ & $\checkmark$ & $\checkmark$ \\
\hline Year dummies & $\checkmark$ & $\checkmark$ & $\checkmark$ & $\checkmark$ & $\checkmark$ & $\checkmark$ & $\checkmark$ & $\checkmark$ \\
\hline Mun FE x Party FE & $\checkmark$ & $\checkmark$ & $\checkmark$ & $\checkmark$ & $\checkmark$ & $\checkmark$ & $\checkmark$ & $\checkmark$ \\
\hline Mean dep. var & 0.028 & 0.039 & 0.897 & 0.045 & 0.043 & 1.715 & 1.521 & 0.194 \\
\hline Effect size $(\Delta \%)$ & 53.2 & 39.0 & 4.6 & -27.2 & -32.8 & 4.9 & 2.7 & 31.1 \\
\hline $95 \%$ CI LB & 25.8 & 16.5 & 2.5 & -48.7 & -55.0 & 1.9 & 0.3 & 19.4 \\
\hline 95\% CI UB & 80.6 & 61.4 & 6.6 & -5.8 & -10.5 & 7.9 & 5.2 & 42.9 \\
\hline Municipalities & 1072 & 1072 & 1101 & 1101 & 1101 & 1101 & 1101 & 1101 \\
\hline Observations & 8668 & 8674 & 18333 & 18365 & 18365 & 18365 & 18365 & 18365 \\
\hline
\end{tabular}

Notes: Standard errors are shown in parenthesis and are clustered at the municipality level. *** denotes statistical significance at the $1 \%$ level, $* * 5 \%$ level, and $* 10 \%$ level. The unit of analysis is a party in a municipality in an election.Pers Camp. Invest. (\% of Campaign limit (Personal investment)), Total Camp. Invest. (\% of Campaign limit (Total investment)), Reg. Vote (Registered to vote in the same place running), Illegal Vote (Registered Illegally to vote), Illegal Vote Diff. (Voted illegally in different polling station), Ran Pub. Office (\# of times cand. ran for any elected post), Ran council (\# of times cand. in list ran for local council), and Councilor (\# of times cand. in list was elected council). 
I. Alternative coding of list positions

I.1. POSITION 2 CODED AS MARGINAL

Table A22: Effect of open list on campaign investment.

\begin{tabular}{|c|c|c|c|c|c|c|c|c|}
\hline & $(1)$ & $(2)$ & $(3)$ & $(4)$ & $(5)$ & $(6)$ & $(7)$ & $(8)$ \\
\hline & \multicolumn{4}{|c|}{$\%$ of Campaign limit (Personal investment) } & \multicolumn{4}{|c|}{$\%$ of Campaign limit (Total investment) } \\
\hline & Average & Top & Marginal & Bottom & Average & Top & Marginal & Bottom \\
\hline Open list & $\begin{array}{c}0.016 \text { *** } \\
(0.004)\end{array}$ & $\begin{array}{c}0.007 \\
(0.008)\end{array}$ & $\begin{array}{c}0.023^{* * *} \\
(0.005)\end{array}$ & $\begin{array}{c}0.018^{* * *} \\
(0.005)\end{array}$ & $\begin{array}{c}0.016^{* * *} \\
(0.004)\end{array}$ & $\begin{array}{c}-0.001 \\
(0.010)\end{array}$ & $\begin{array}{c}0.024^{* * *} \\
(0.006)\end{array}$ & $\begin{array}{c}0.022^{* * *} \\
(0.005)\end{array}$ \\
\hline Year dummies & $\checkmark$ & $\checkmark$ & $\checkmark$ & $\checkmark$ & $\checkmark$ & $\checkmark$ & $\checkmark$ & $\checkmark$ \\
\hline Mun FE x Party FE & $\checkmark$ & $\checkmark$ & $\checkmark$ & $\checkmark$ & $\checkmark$ & $\checkmark$ & $\checkmark$ & $\checkmark$ \\
\hline Mean dep. var & 0.028 & 0.039 & 0.029 & 0.026 & 0.039 & 0.080 & 0.044 & 0.033 \\
\hline Effect size $(\Delta \%)$ & 57.2 & 18.1 & 78.0 & 72.0 & 42.2 & -1.3 & 55.5 & 66.4 \\
\hline $95 \%$ CI LB & 29.8 & -23.3 & 42.0 & 36.3 & 19.6 & -26.9 & 27.8 & 36.9 \\
\hline $95 \%$ CI UB & 84.6 & 59.5 & 114.0 & 107.8 & 64.7 & 24.3 & 83.2 & 96.0 \\
\hline Municipalities & 1072 & 1022 & 1009 & 1065 & 1072 & 1022 & 1010 & 1065 \\
\hline Observations & 8668 & 6487 & 5904 & 8230 & 8674 & 6497 & 5912 & 8244 \\
\hline
\end{tabular}

Notes: Standard errors are shown in parenthesis and are clustered at the municipality level. *** denotes statistical significance at the $1 \%$ level, ${ }^{* *} 5 \%$ level, and $* 10 \%$ level. The unit of analysis is a party in a municipality in an election. Top are candidates located at the top of the list before the election, marginal candidates are located in the second position, and bottom are third to last candidates in the list. 
Table A23: Effect of open list on political experience

\begin{tabular}{|c|c|c|c|c|c|c|c|c|}
\hline & $(1)$ & $(2)$ & $(3)$ & $(4)$ & $(5)$ & $(6)$ & $(7)$ & $(8)$ \\
\hline & \multicolumn{4}{|c|}{ \# of times cand. ran any post } & \multicolumn{4}{|c|}{ \# of times cand. ran council } \\
\hline & Average & Top & Marginal & Bottom & Average & Top & Marginal & Bottom \\
\hline Open list & $\begin{array}{c}0.081^{* * *} \\
(0.026)\end{array}$ & $\begin{array}{c}0.008 \\
(0.053)\end{array}$ & $\begin{array}{c}0.044 \\
(0.058)\end{array}$ & $\begin{array}{c}0.187^{* * *} \\
(0.026)\end{array}$ & $\begin{array}{l}0.036^{*} \\
(0.019)\end{array}$ & $\begin{array}{c}0.000 \\
(0.044)\end{array}$ & $\begin{array}{c}0.031 \\
(0.045)\end{array}$ & $\begin{array}{c}0.099 * * * \\
(0.021)\end{array}$ \\
\hline Year dummies & $\checkmark$ & $\checkmark$ & $\checkmark$ & $\checkmark$ & $\checkmark$ & $\checkmark$ & $\checkmark$ & $\checkmark$ \\
\hline Mun FE x Party FE & $\checkmark$ & $\checkmark$ & $\checkmark$ & $\checkmark$ & $\checkmark$ & $\checkmark$ & $\checkmark$ & $\checkmark$ \\
\hline Mean dep. var & 1.715 & 2.130 & 1.855 & 1.582 & 1.521 & 1.814 & 1.626 & 1.429 \\
\hline Effect size $(\Delta \%)$ & 4.7 & 0.4 & 2.4 & 11.8 & 2.4 & 0.0 & 1.9 & 6.9 \\
\hline $95 \%$ CI LB & 1.7 & -4.4 & -3.7 & 8.6 & -0.1 & -4.7 & -3.6 & 4.1 \\
\hline $95 \%$ CI UB & 7.7 & 5.2 & 8.5 & 15.1 & 4.8 & 4.7 & 7.4 & 9.8 \\
\hline Municipalities & 1101 & 1101 & 1101 & 1101 & 1101 & 1101 & 1101 & 1101 \\
\hline \multirow[t]{4}{*}{ Observations } & 18365 & 18206 & 17849 & 17774 & 18365 & 18206 & 17849 & 17774 \\
\hline & $(11)$ & $(12)$ & $(13)$ & $(14)$ & & & & \\
\hline & \multicolumn{4}{|c|}{ \# of times cand. in list was councilor } & & & & \\
\hline & Average & Top & Marginal & Bottom & & & & \\
\hline Open list & $\begin{array}{c}0.058^{* * *} \\
(0.012)\end{array}$ & $\begin{array}{c}-0.085^{* *} \\
(0.036)\end{array}$ & $\begin{array}{l}-0.008 \\
(0.035)\end{array}$ & $\begin{array}{c}0.110^{* * *} \\
(0.012)\end{array}$ & & & & \\
\hline Year dummies & $\checkmark$ & $\checkmark$ & $\checkmark$ & $\checkmark$ & & & & \\
\hline Mun FE x Party FE & $\checkmark$ & $\checkmark$ & $\checkmark$ & $\checkmark$ & & & & \\
\hline Mean dep. var & 0.194 & 0.507 & 0.274 & 0.131 & & & & \\
\hline Effect size $(\Delta \%)$ & 29.8 & -16.8 & -3.0 & 83.9 & & & & \\
\hline $95 \%$ CI LB & 18.0 & -30.7 & -27.7 & 66.1 & & & & \\
\hline $95 \%$ CI UB & 41.5 & -2.8 & 21.8 & 101.8 & & & & \\
\hline Municipalities & 1101 & 1101 & 1101 & 1101 & & & & \\
\hline Observations & 18365 & 18206 & 17849 & 17774 & & & & \\
\hline
\end{tabular}

Notes: Standard errors are shown in parenthesis and are clustered at the municipality level. *** denotes statistical significance at the $1 \%$ level, ${ }^{* *} 5 \%$ level, and $* 10 \%$ level. The unit of analysis is a party in a municipality in an election. Top are candidates located at the top of the list before the election, marginal candidates are located in the second and third position, and bottom are fourth to last candidates in the list. 


\section{Table A24: Effect of list type on engagement in constituency}

\begin{tabular}{lcccc}
\hline \hline & $(1)$ & $(2)$ & $(3)$ & $(4)$ \\
& Average & Top & Marginal & Bottom \\
\hline & & & & \\
Open list & $0.042^{* * *}$ & $0.071^{* * *}$ & $0.036^{* *}$ & $0.041^{* * *}$ \\
& $(0.009)$ & $(0.018)$ & $(0.018)$ & $(0.011)$ \\
& & & & \\
Year dummies & $\checkmark$ & $\checkmark$ & $\checkmark$ & $\checkmark$ \\
Mun FE x Party FE & $\checkmark$ & $\checkmark$ & $\checkmark$ & $\checkmark$ \\
& & & & \\
Mean dep. var & 0.897 & 0.889 & 0.900 & 0.899 \\
Effect Size ( $\Delta$ \%) & 4.6 & 8.0 & 4.0 & 4.6 \\
95\% CI LB & 2.6 & 4.1 & 0.2 & 2.1 \\
95\% CI UB & 6.7 & 12.0 & 7.8 & 7.0 \\
Municipalities & 1101 & 1101 & 1101 & 1101 \\
Observations & 18333 & 16944 & 16533 & 17723 \\
\hline \hline
\end{tabular}

Notes: Standard errors are shown in parenthesis and are clustered at the municipality level. *** denotes statistical significance at the $1 \%$ level, $* * 5 \%$ level, and $* 10 \%$ level. The unit of analysis is a party in a municipality in an election. Top are candidates located at the top of the list before the election, marginal candidates are located in the second position, and bottom are third to last candidates in the list.

\section{Table A25: Effect of open list on election fraud}

\begin{tabular}{|c|c|c|c|c|c|c|c|c|}
\hline & (1) & $(2)$ & $(3)$ & $(4)$ & $(5)$ & $(6)$ & (7) & $(8)$ \\
\hline & \multicolumn{4}{|c|}{ Registered Ilegally to vote } & \multicolumn{4}{|c|}{ Voted illegally in different polling station } \\
\hline & Average & Top & Marginal & Bottom & Average & Top & Marginal & Bottom \\
\hline Open list & $\begin{array}{c}-0.013^{* *} \\
(0.005)\end{array}$ & $\begin{array}{c}-0.016 \\
(0.012)\end{array}$ & $\begin{array}{c}-0.024^{* *} \\
(0.011)\end{array}$ & $\begin{array}{c}-0.012^{*} \\
(0.007)\end{array}$ & $\begin{array}{c}-0.014^{* * *} \\
(0.005)\end{array}$ & $\begin{array}{c}-0.021^{*} \\
(0.011)\end{array}$ & $\begin{array}{c}-0.025^{* *} \\
(0.011)\end{array}$ & $\begin{array}{c}-0.012^{*} \\
(0.007)\end{array}$ \\
\hline Year dummies & $\checkmark$ & $\checkmark$ & $\checkmark$ & $\checkmark$ & $\checkmark$ & $\checkmark$ & $\checkmark$ & $\checkmark$ \\
\hline Mun FE x Party FE & $\checkmark$ & $\checkmark$ & $\checkmark$ & $\checkmark$ & $\checkmark$ & $\checkmark$ & $\checkmark$ & $\checkmark$ \\
\hline Mean Dep. Var & 0.045 & 0.048 & 0.042 & 0.043 & 0.043 & 0.042 & 0.037 & 0.042 \\
\hline Effect Size $(\Delta \%)$ & -27.8 & -34.5 & -56.9 & -27.8 & -33.4 & -49.9 & -65.7 & -28.4 \\
\hline $95 \%$ CI LB & -49.1 & -81.8 & -109.9 & -58.5 & -55.5 & -101.5 & -122.7 & -59.6 \\
\hline $95 \%$ CI UB & -6.5 & 12.8 & -3.8 & 2.8 & -11.3 & 1.6 & -8.7 & 2.7 \\
\hline Municipalities & 1101 & 1101 & 1101 & 1101 & 1101 & 1101 & 1101 & 1101 \\
\hline Observations & 18365 & 18201 & 17837 & 17774 & 18365 & 18201 & 17837 & 17774 \\
\hline
\end{tabular}

Notes: Standard errors are shown in parenthesis and are clustered at the municipality level. ${ }^{* * *}$ denotes statistical significance at the $1 \%$ level, $* * 5 \%$ level, and $* 10 \%$ level. The unit of analysis is a party in a municipality in an election. Top are candidates located at the top of the list before the election, marginal candidates are located in the second position, and bottom are third to last candidates in the list. 
I.2. Robustness tests With List positions 2, 3 And 4 COded AS MARginal

Table A26: Effect of open list on campaign investment

\begin{tabular}{|c|c|c|c|c|c|c|c|c|}
\hline & $(1)$ & $(2)$ & $(3)$ & $(4)$ & $(5)$ & $(6)$ & (7) & $(8)$ \\
\hline & \multicolumn{4}{|c|}{$\%$ of Campaign limit (Personal investment) } & \multicolumn{4}{|c|}{$\%$ of Campaign limit (Total investment) } \\
\hline & Average & Top & Marginal & Bottom & Average & Top & Marginal & Bottom \\
\hline Open list & $\begin{array}{c}0.016^{* * *} \\
(0.004)\end{array}$ & $\begin{array}{c}0.007 \\
(0.008)\end{array}$ & $\begin{array}{c}0.020 * * * \\
(0.005)\end{array}$ & $\begin{array}{c}0.019 * * * \\
(0.005)\end{array}$ & $\begin{array}{c}0.016^{* * *} \\
(0.004)\end{array}$ & $\begin{array}{c}-0.001 \\
(0.010)\end{array}$ & $\begin{array}{c}0.020^{* * *} \\
(0.005)\end{array}$ & $\begin{array}{c}0.025^{* * *} \\
(0.006)\end{array}$ \\
\hline Year dummies & $\checkmark$ & $\checkmark$ & $\checkmark$ & $\checkmark$ & $\checkmark$ & $\checkmark$ & $\checkmark$ & $\checkmark$ \\
\hline Mun FE x Party FE & $\checkmark$ & $\checkmark$ & $\checkmark$ & $\checkmark$ & $\checkmark$ & $\checkmark$ & $\checkmark$ & $\checkmark$ \\
\hline Mean dep. var & 0.028 & 0.039 & 0.027 & 0.028 & 0.039 & 0.080 & 0.037 & 0.035 \\
\hline Effect size $(\Delta \%)$ & 57.2 & 18.1 & 73.5 & 66.9 & 42.2 & -1.3 & 54.6 & 72.0 \\
\hline $95 \%$ CI LB & 29.8 & -23.3 & 41.2 & 28.8 & 19.6 & -26.9 & 27.8 & 38.9 \\
\hline $95 \%$ CI UB & 84.6 & 59.5 & 105.9 & 105.0 & 64.7 & 24.3 & 81.3 & 105.1 \\
\hline Municipalities & 1072 & 1022 & 1051 & 1057 & 1072 & 1022 & 1052 & 1057 \\
\hline Observations & 8668 & 6487 & 7559 & 7755 & 8674 & 6497 & 7571 & 7769 \\
\hline
\end{tabular}

Notes: Standard errors are shown in parenthesis and are clustered at the municipality level. *** denotes statistical significance at the $1 \%$ level, ${ }^{* *} 5 \%$ level, and $* 10 \%$ level. The unit of analysis is a party in a municipality in an election. Top are candidates located at the top of the list before the election, marginal candidates are located in the second, third and fourth position, and bottom are fifth to last candidates on the list. 
Table A27: Effect of open list on political experience

\begin{tabular}{|c|c|c|c|c|c|c|c|c|}
\hline & \multirow{2}{*}{\multicolumn{4}{|c|}{$\begin{array}{l}(1) \quad(2) \\
\text { \# of times cand. ran for any post }\end{array}$}} & $(5)$ & $(6)$ & $(7)$ & $(8)$ \\
\hline & & & & & \multicolumn{4}{|c|}{ \# of times cand. ran council } \\
\hline & Average & Top & Marginal & Bottom & Average & Top & Marginal & Bottom \\
\hline Open list & $\begin{array}{c}0.081^{* * * *} \\
(0.026)\end{array}$ & $\begin{array}{c}0.008 \\
(0.053)\end{array}$ & $\begin{array}{c}0.086^{* *} \\
(0.034)\end{array}$ & $\begin{array}{c}0.283^{* * *} \\
(0.032)\end{array}$ & $\begin{array}{l}0.036^{*} \\
(0.019)\end{array}$ & $\begin{array}{c}0.000 \\
(0.044)\end{array}$ & $\begin{array}{l}0.049^{*} \\
(0.027)\end{array}$ & $\begin{array}{c}0.176^{* * *} \\
(0.025)\end{array}$ \\
\hline Year dummies & $\checkmark$ & $\checkmark$ & $\checkmark$ & $\checkmark$ & $\checkmark$ & $\checkmark$ & $\checkmark$ & $\checkmark$ \\
\hline Mun FE x Party FE & $\checkmark$ & $\checkmark$ & $\checkmark$ & $\checkmark$ & $\checkmark$ & $\checkmark$ & $\checkmark$ & $\checkmark$ \\
\hline Mean dep. var & 1.715 & 2.130 & 1.725 & 1.572 & 1.521 & 1.814 & 1.535 & 1.407 \\
\hline Effect size $(\Delta \%)$ & 4.7 & 0.4 & 5.0 & 18.0 & 2.4 & 0.0 & 3.2 & 12.5 \\
\hline $95 \%$ CI LB & 1.7 & -4.4 & 1.1 & 14.0 & -0.1 & -4.7 & -0.2 & 9.1 \\
\hline $95 \%$ CI UB & 7.7 & 5.2 & 8.9 & 22.0 & 4.8 & 4.7 & 6.6 & 16.0 \\
\hline Municipalities & 1101 & 1101 & 1101 & 1101 & 1101 & 1101 & 1101 & 1101 \\
\hline \multirow[t]{4}{*}{ Observations } & 18365 & 18206 & 18114 & 16597 & 18365 & 18206 & 18114 & 16597 \\
\hline & $(11)$ & $(12)$ & $(13)$ & $(14)$ & & & & \\
\hline & \# of tim & es cand. & in list was & councilor & & & & \\
\hline & Average & Top & Marginal & Bottom & & & & \\
\hline Open list & $\begin{array}{c}0.058^{* * *} \\
(0.012)\end{array}$ & $\begin{array}{c}-0.085^{* *} \\
(0.036)\end{array}$ & $\begin{array}{c}0.058^{* * *} \\
(0.019)\end{array}$ & $\begin{array}{c}0.140 * * * \\
(0.017)\end{array}$ & & & & \\
\hline Year dummies & $\checkmark$ & $\checkmark$ & $\checkmark$ & $\checkmark$ & & & & \\
\hline Mun FE x Party FE & $\checkmark$ & $\checkmark$ & $\checkmark$ & $\checkmark$ & & & & \\
\hline Mean dep. var & 0.194 & 0.507 & 0.204 & 0.143 & & & & \\
\hline Effect size $(\Delta \%)$ & 29.8 & -16.8 & 28.5 & 98.1 & & & & \\
\hline $95 \%$ CI LB & 18.0 & -30.7 & 10.4 & 74.5 & & & & \\
\hline $95 \%$ CI UB & 41.5 & -2.8 & 46.7 & 121.6 & & & & \\
\hline Municipalities & 1101 & 1101 & 1101 & 1101 & & & & \\
\hline Observations & 18365 & 18206 & 18114 & 16597 & & & & \\
\hline
\end{tabular}

Notes: Standard errors are shown in parenthesis and are clustered at the municipality level. *** denotes statistical significance at the $1 \%$ level, ${ }^{* *} 5 \%$ level, and $* 10 \%$ level. The unit of analysis is a party in a municipality in an election. Top are candidates located at the top of the list before the election, marginal candidates are located in the second, third and fourth position, and bottom are fifth to last candidates on the list. 


\section{Table A28: Effect of list type on engagement in constituency}

\begin{tabular}{lcccc}
\hline \hline & $(1)$ & $(2)$ & $(3)$ & $(4)$ \\
& Average & Top & Marginal & Bottom \\
\hline & & & & \\
Open list & $0.042^{* * *}$ & $0.071^{* * *}$ & $0.039^{* * *}$ & $0.037^{* * *}$ \\
& $(0.009)$ & $(0.018)$ & $(0.012)$ & $(0.014)$ \\
& & & & \\
Year dummies & $\checkmark$ & $\checkmark$ & $\checkmark$ & $\checkmark$ \\
Mun FE x Party FE & $\checkmark$ & $\checkmark$ & $\checkmark$ & $\checkmark$ \\
& & & & \\
Mean Dep. Var & 0.897 & 0.889 & 0.900 & 0.906 \\
Effect Size $(\Delta \%)$ & 4.7 & 8.03 & 4.4 & 4.037 \\
95\% CI LB & 2.6 & 4.1 & 1.8 & 1.0 \\
95\% CI UB & 6.7 & 12.0 & 7.0 & 7.1 \\
Municipalities & 1101 & 1101 & 1101 & 1101 \\
Observations & 18333 & 16944 & 18056 & 16510 \\
\hline \hline
\end{tabular}

Notes: Standard errors are shown in parenthesis and are clustered at the municipality level. *** denotes statistical significance at the $1 \%$ level, $* * 5 \%$ level, and $* 10 \%$ level. The unit of analysis is a party in a municipality in an election. Top are candidates located at the top of the list before the election, marginal candidates are located in the second, third and fourth position, and bottom are fifth to last candidates on the list.

\section{Table A29: Effect of open list on election fraud}

\begin{tabular}{|c|c|c|c|c|c|c|c|c|}
\hline & (1) & $(2)$ & $(3)$ & $(4)$ & $(5)$ & $(6)$ & $(7)$ & $(8)$ \\
\hline & \multicolumn{4}{|c|}{ Registered Ilegally to vote } & \multicolumn{4}{|c|}{ Voted illegally in different polling station } \\
\hline & Average & Top & Marginal & Bottom & Average & Top & Marginal & Bottom \\
\hline Open list & $\begin{array}{c}-0.013^{* *} \\
(0.005)\end{array}$ & $\begin{array}{l}-0.016 \\
(0.012)\end{array}$ & $\begin{array}{c}-0.021^{* * *} \\
(0.008)\end{array}$ & $\begin{array}{c}-0.013 \\
(0.008)\end{array}$ & $\begin{array}{c}-0.014^{* * *} \\
(0.005)\end{array}$ & $\begin{array}{c}-0.021^{*} \\
(0.011)\end{array}$ & $\begin{array}{c}-0.023^{* * *} \\
(0.007)\end{array}$ & $\begin{array}{l}-0.012 \\
(0.008)\end{array}$ \\
\hline Year dummies & $\checkmark$ & $\checkmark$ & $\checkmark$ & $\checkmark$ & $\checkmark$ & $\checkmark$ & $\checkmark$ & $\checkmark$ \\
\hline Mun FE x Party FE & $\checkmark$ & $\checkmark$ & $\checkmark$ & $\checkmark$ & $\checkmark$ & $\checkmark$ & $\checkmark$ & $\checkmark$ \\
\hline Mean Dep. Var & 0.045 & 0.048 & 0.044 & 0.041 & 0.043 & 0.042 & 0.042 & 0.039 \\
\hline Effect Size $(\Delta \%)$ & -27.8 & -34.5 & -47.7 & -31.1 & -33.4 & -49.9 & -53.8 & -29.9 \\
\hline $95 \%$ CI LB & -49.1 & -81.8 & -81.6 & -68.4 & -55.5 & -101.5 & -88.2 & -68.9 \\
\hline $95 \%$ CI UB & -6.5 & 12.8 & -13.8 & 6.3 & -11.3 & 1.6 & -19.4 & 9.0 \\
\hline Municipalities & 1101 & 1101 & 1101 & 1101 & 1101 & 1101 & 1101 & 1101 \\
\hline Observations & 18365 & 18201 & 18114 & 16596 & 18365 & 18201 & 18114 & 16596 \\
\hline
\end{tabular}

Notes: Standard errors are shown in parenthesis and are clustered at the municipality level. *** denotes statistical significance at the $1 \%$ level, $* * 5 \%$ level, and $* 10 \%$ level. The unit of analysis is a party in a municipality in an election. Top are candidates located at the top of the list before the election, marginal candidates are located in the second, third and fourth position, and bottom are fifth to last candidates on the list. 
J. Additional results

Table A30: Effect of use of closed lists on municipality electoral outcomes

\begin{tabular}{|c|c|c|c|}
\hline & $\begin{array}{c}\text { (1) } \\
\text { voter turnout }\end{array}$ & $\begin{array}{c}(2) \\
\% \text { of invalid votes }\end{array}$ & $\begin{array}{c}(3) \\
\% \text { of unmarked votes }\end{array}$ \\
\hline$\%$ of parties with closed lists & $\begin{array}{l}-0.0166 \\
(0.0111)\end{array}$ & $\begin{array}{l}-0.00289 \\
(0.00326)\end{array}$ & $\begin{array}{c}0.0321^{* * *} \\
(0.00387)\end{array}$ \\
\hline Constant & $\begin{array}{l}0.540^{* * *} \\
(0.00230)\end{array}$ & $\begin{array}{l}0.0788 * * * \\
(0.000392)\end{array}$ & $\begin{array}{l}0.0505^{* * *} \\
(0.000466)\end{array}$ \\
\hline $\begin{array}{c}\text { Mun FE } \\
\text { Year FE } \\
\text { Observations } \\
\text { R2 Adjusted }\end{array}$ & $\begin{array}{c}\checkmark \\
\checkmark \\
4385 \\
0.385\end{array}$ & $\begin{array}{c}\checkmark \\
\checkmark \\
3295 \\
0.646\end{array}$ & $\begin{array}{c}\checkmark \\
\checkmark \\
3294 \\
-0.204\end{array}$ \\
\hline $\begin{array}{l}=1 \text { if municipality had } \\
\text { at least one closed list }\end{array}$ & $\begin{array}{c}0.00412 \\
(0.00268)\end{array}$ & $\begin{array}{c}0.000829 \\
(0.000629)\end{array}$ & $\begin{array}{c}0.00217^{* * *} \\
(0.000758)\end{array}$ \\
\hline Constant & $\begin{array}{l}0.536^{* * *} \\
(0.00228)\end{array}$ & $\begin{array}{l}0.0785 * * * \\
(0.000393)\end{array}$ & $\begin{array}{l}0.0512^{* * *} \\
(0.000474)\end{array}$ \\
\hline Mun FE & $\checkmark$ & $\checkmark$ & $\checkmark$ \\
\hline Year FE & $\checkmark$ & $\checkmark$ & $\checkmark$ \\
\hline Observations & 4385 & 3295 & 3294 \\
\hline R2 Adjusted & 0.385 & 0.646 & -0.238 \\
\hline
\end{tabular}

Notes: Standard errors are shown in parenthesis and are clustered at the municipality level. *** denotes statistical significance at the $1 \%$ level, ${ }^{* *} 5 \%$ level, and $* 10 \%$ level. The unit of analysis is a party in a municipality in an election. 


\section{Table A31: Position change of candidate placement in list after election Open lists only.}

\begin{tabular}{|c|c|c|c|}
\hline \multirow{2}{*}{$\begin{array}{l}\text { Change in } \\
\text { position }\end{array}$} & \multicolumn{2}{|c|}{ Proportion of candidates: } & \multirow{2}{*}{$\begin{array}{c}\text { t-test } \\
\text { Difference }\end{array}$} \\
\hline & Other candidates & Candidates who: & \\
\hline position change & other cand. & did pers. campaign invest. & \\
\hline lower & 0.485 & 0.394 & $0.091^{* * *}$ \\
\hline same & 0.141 & 0.131 & $0.010^{* * *}$ \\
\hline higher & 0.374 & 0.475 & $-0.101^{* * *}$ \\
\hline position change & other cand. & did tot. campaign invest. & \\
\hline lower & 0.486 & 0.393 & $0.093^{* * *}$ \\
\hline same & 0.140 & 0.132 & $0.008^{* * *}$ \\
\hline higher & 0.374 & 0.475 & $-0.101^{* * *}$ \\
\hline position change & other cand. & regis. vote same place & \\
\hline lower & 0.508 & 0.443 & $0.065^{* * *}$ \\
\hline same & 0.164 & 0.146 & $0.019 * * *$ \\
\hline higher & 0.328 & 0.412 & $-0.084 * * *$ \\
\hline position change & other cand. & regis. vote ilegally & \\
\hline lower & 0.448 & 0.513 & $-0.065^{* * *}$ \\
\hline same & 0.147 & 0.149 & -0.001 \\
\hline higher & 0.405 & 0.339 & $0.066^{* * *}$ \\
\hline position change & other cand. & regis. vote ilegal. another place & \\
\hline lower & 0.448 & 0.515 & $-0.067 * * *$ \\
\hline same & 0.147 & 0.149 & -0.001 \\
\hline higher & 0.405 & 0.336 & $0.069^{* * *}$ \\
\hline position change & other cand. & ran pub. office & \\
\hline lower & 0.498 & 0.397 & $0.101^{* * *}$ \\
\hline same & 0.140 & 0.155 & $-0.015^{* * *}$ \\
\hline higher & 0.361 & 0.447 & $-0.086^{* * *}$ \\
\hline position change & other cand. & ran for council & \\
\hline lower & 0.494 & 0.384 & $0.110^{* * *}$ \\
\hline same & 0.143 & 0.155 & $-0.012 * * *$ \\
\hline higher & 0.363 & 0.462 & $-0.098 * * *$ \\
\hline position change & other cand. & was councilor & \\
\hline lower & 0.519 & 0.239 & $0.279^{* * *}$ \\
\hline same & 0.138 & 0.178 & $-0.040 * * *$ \\
\hline higher & 0.344 & 0.583 & $-0.239 * * *$ \\
\hline
\end{tabular}

Note: Standard errors are shown in parenthesis and are clustered at the municipality level. *** denotes statistical significance at the $1 \%$ level, ${ }^{* *} 5 \%$ level, and $* 10 \%$ level. 